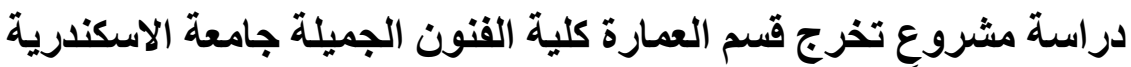

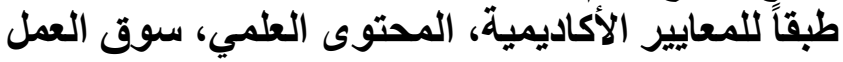 \\ ولاء السيد يوسف \\ مدرس بقسم العمارة كلبة الفنون الجمبلة جامعة الإسكندرية \\ تاريخ الورود 22 سبتمبر ، تاريخ القبول 11 نوفمبر 2013
}

الملخص:

يعتبر تطوير التعليم المعماري من الأولويات القصوى لدى جامعات مصر الخاصة و الحكومية على حدٍ

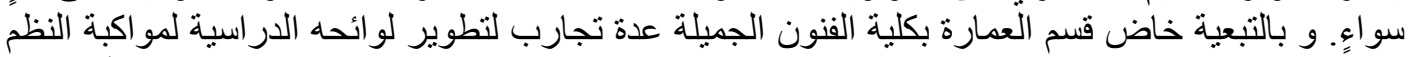

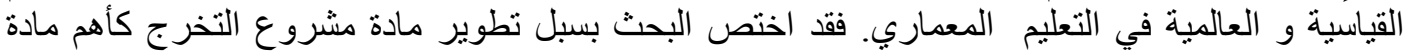

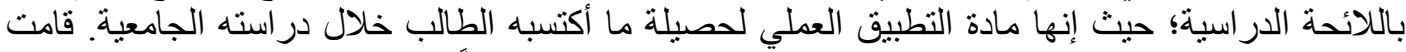

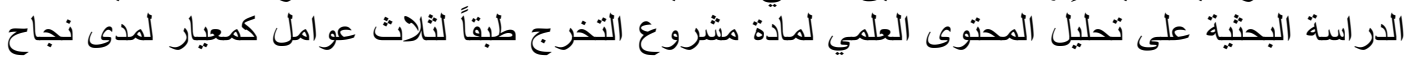

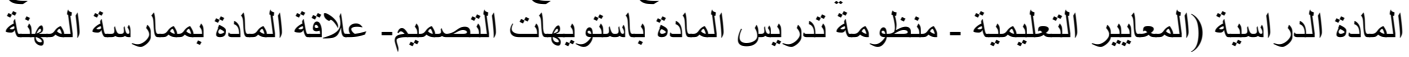

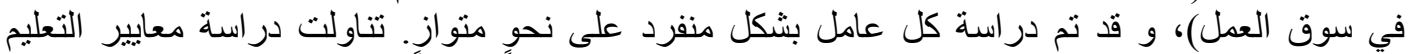

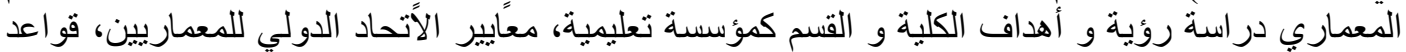

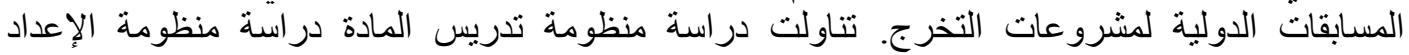

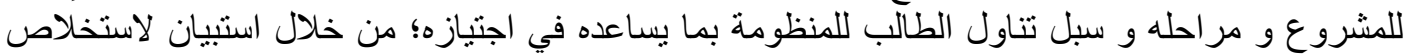

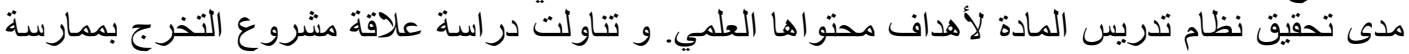

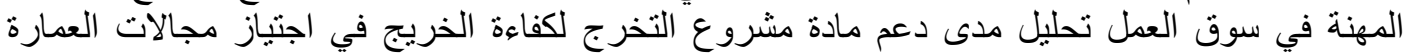

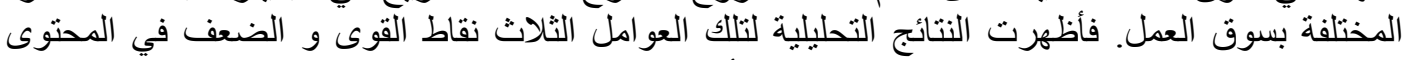

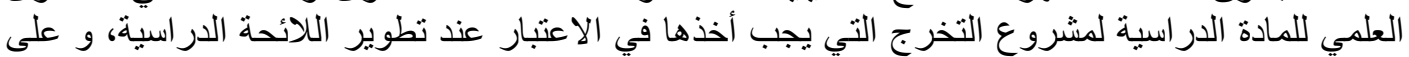

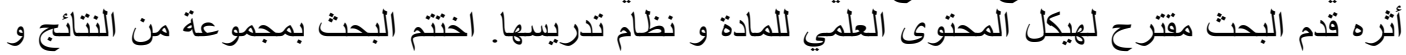
التوصيات التي تسهم في جزء فه من تطوير التعليم المعماري. كلمات البحث: مشروع تخرج العمارة، المحتوى العلمي، التعليم المعماري، سوق العمل.

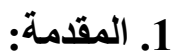

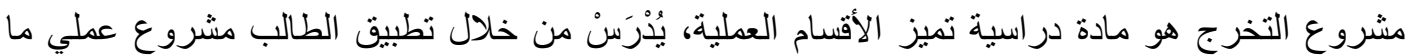

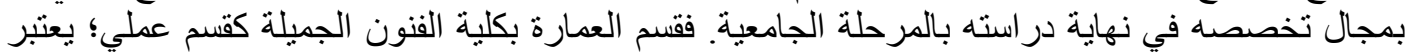

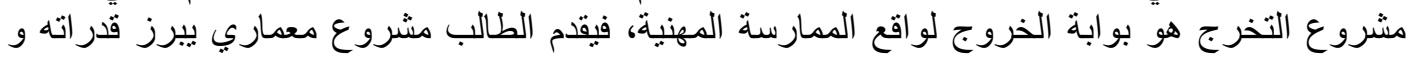
مهار اته كمهندس معماري. 1.1. الهوف و المنهجية و الأ همية: يهذف البحث المشاركة في تطوير اللوائح الدر اسية، و ذلك بمحاولة الاسهام في تطوير مادة مشروع التخرج كأكثر مادة في اللائحة الدر اسية اهمية لما لها من عدد ساعات و درجات درات تقيمية؛ و لكونها مادة التطبيق العملي فئي

Corresponding author.

E- Mail address: sehammnofal@yahoo.com 
ولاء السيد يوسف، دراسة مشروع تخرج قسم العمارة كلية الفنون الجميلة جامعة الإسكندرية طبقاً للمعابير الأكاديمية،

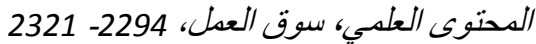

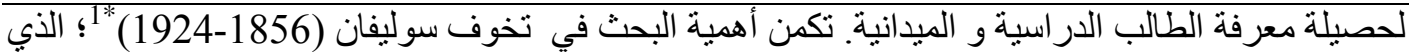

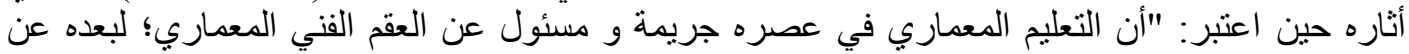

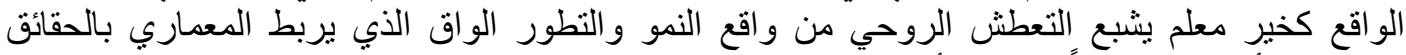

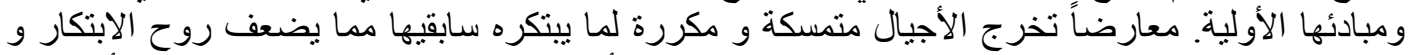

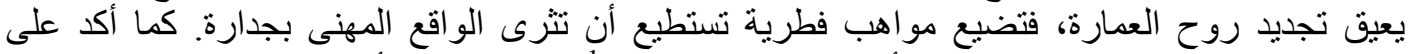

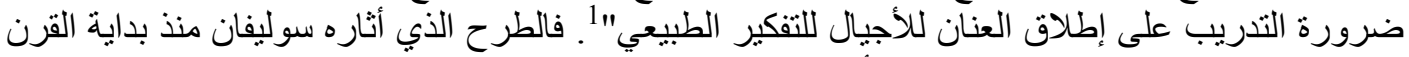

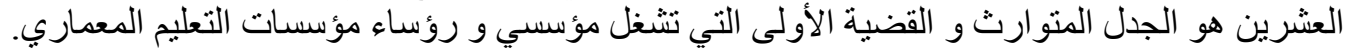

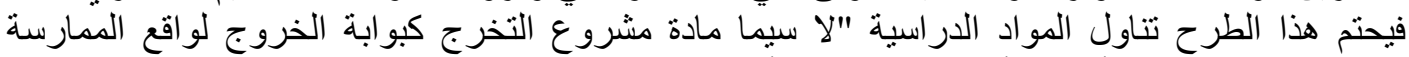

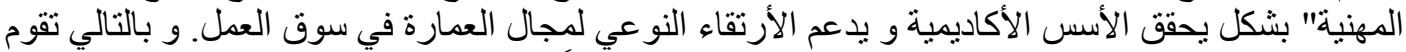

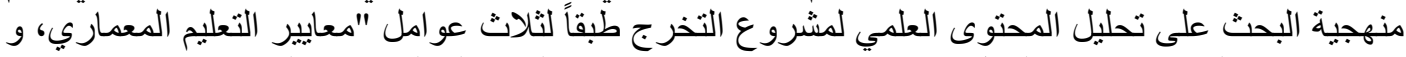

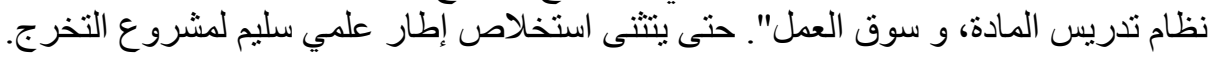

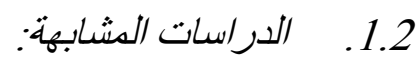

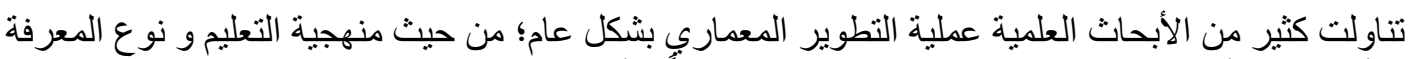

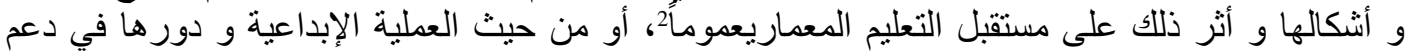

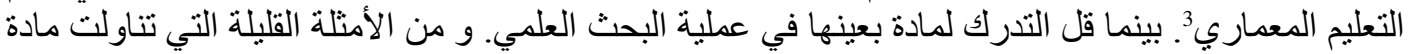

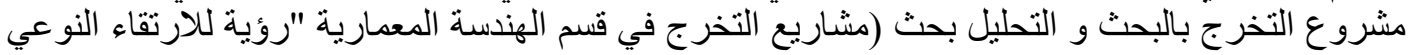

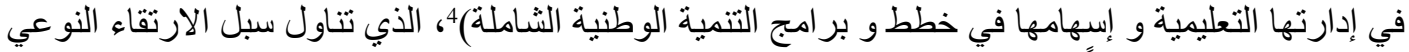

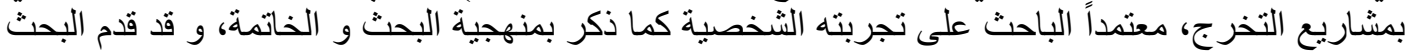

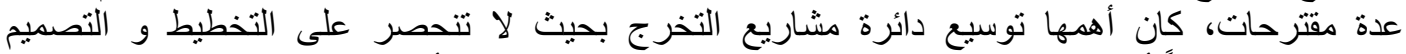

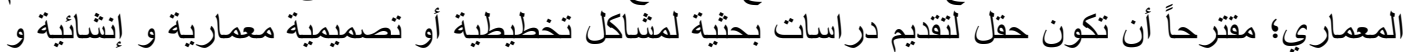
بيئية ذات علاقة بالعمارة و التراث المعماري التفائ در الحفاظ عليه.

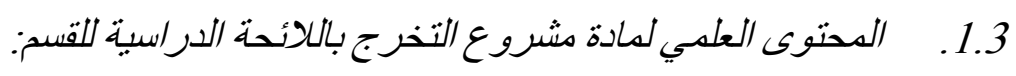

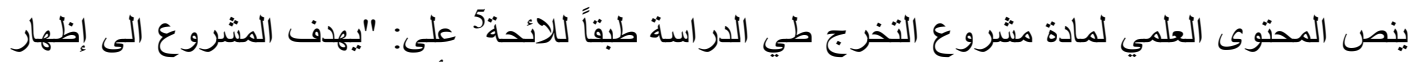

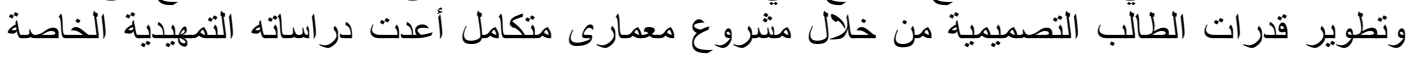

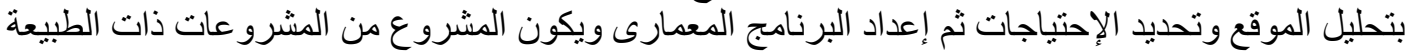

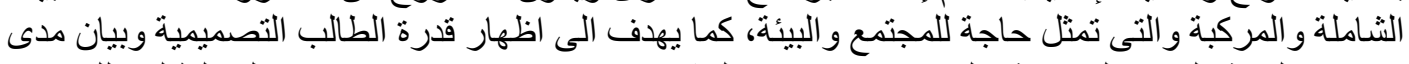

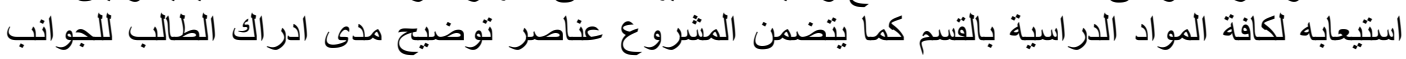
التخطيطية للتصميم المعمارى و التفاصيل المعمارية الخاصة بالمبنى المبنى".

\section{2. - 2. معايير التعليم المعماري:}

قامت الدراسة البحثية على جمع المعايير التعليمية الممكنة لمجال العمارة لتكون الأساس المنهجي في تحليل

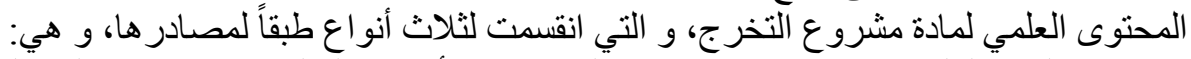

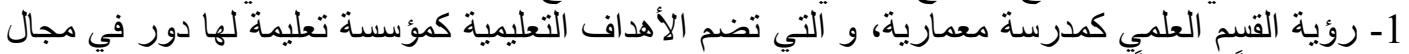

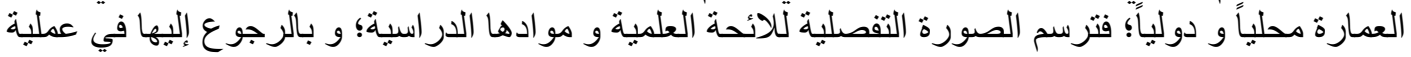

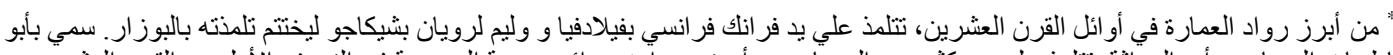

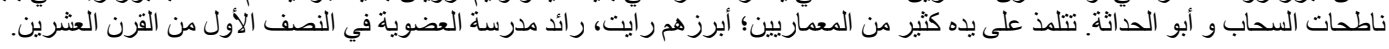

Journal of Engineering Sciences, Assiut University, Faculty of Engineering, Vol. 41, No. 6, November, 2013,E-mail address: jes@aun.edu.eg 
ولاء السيد يوسف، دراسة مشروع تخرج قسم العمارة كلية الفنون الجميلة جامعة الإسكندرية طبقاً للمعايير الأكاديمية،

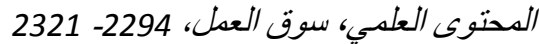

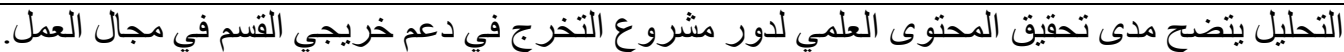

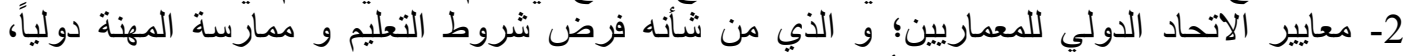

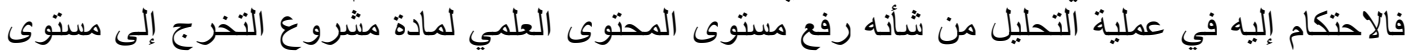
المعايير الدولية في مجال العمارة.

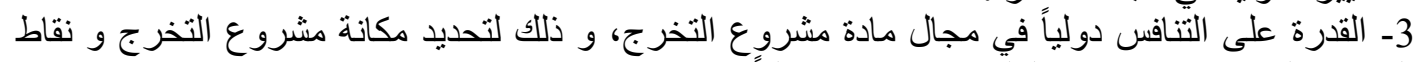
القوى و الضعف في محتو اه العلمي بين قر ائنه دولياً.

$$
\text { 1.2. الرؤية و الأهداف للقسم العلمي: }
$$

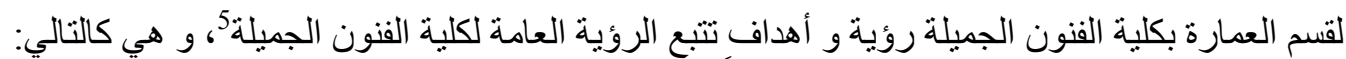

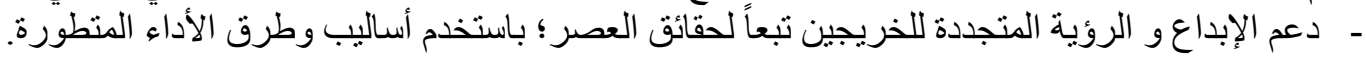

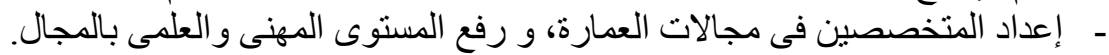

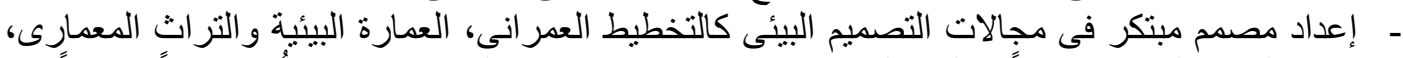

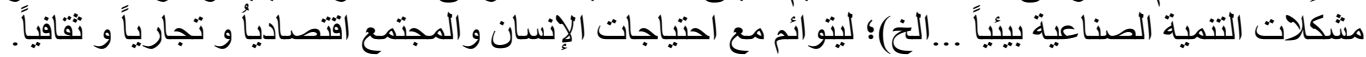

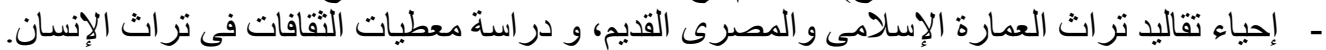

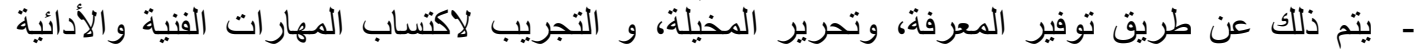

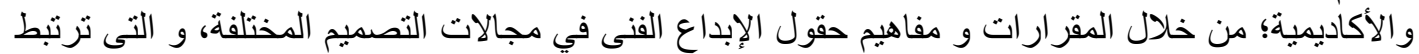
بالأساس المعرفى للممارسة العملية. 2.2. معايير الاتحاد الدولي للمعداريين:

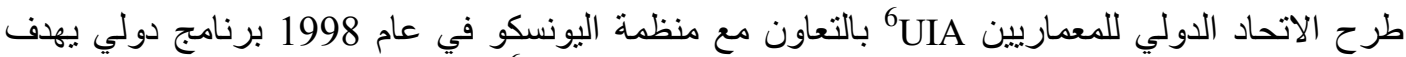

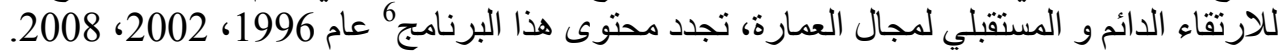
1.2.2 المعايير المنية لمجال العمارة6:

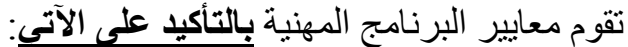

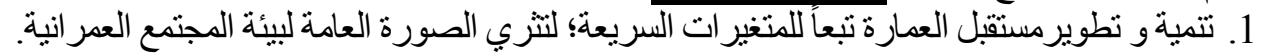

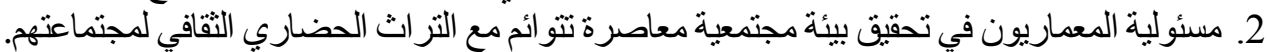

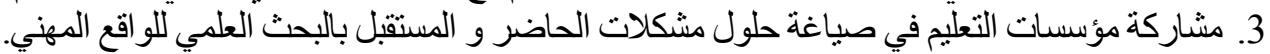

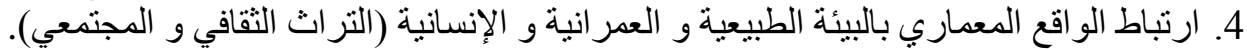

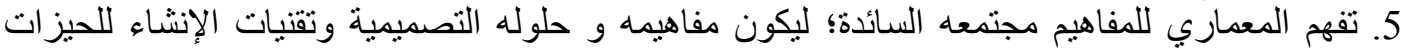

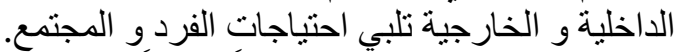

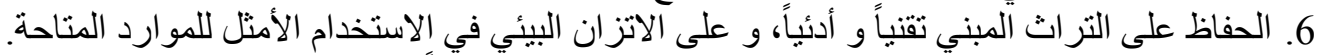
7. إثر اء منهجيات و أساليب ومصادي الينيأ تعليم و تدريب و المعماريين ثقافياً.

Journal of Engineering Sciences, Assiut University, Faculty of Engineering, Vol. 41, No. 6, November, 2013,E-mail address: jes@aun.edu.eg 
ولاء السبي بوسف، دراسة مشروع تخرج قسم العدارة كلية الفنون الجمبلة جامعة الإسكندرية طبقاً للمعابيير الأكاديبية، المحتوى العلدي، سوق العمل، 2294- 2321

$$
\text { 2.2.2. المعابير الأكاديمبة لمجال العدارة 6. }
$$

1. أن تقوم مؤسسات التعليم المعماري على تحقيق نظام التقويم الذاتي و توفير أنظمة أخرى كتقييم الجامعات الأخرى و المعماربين المؤنسار التعين. 2. تشجيع التعاون المستمر بين المعماريين المينين المهنيين والمؤسسات التعليمية.

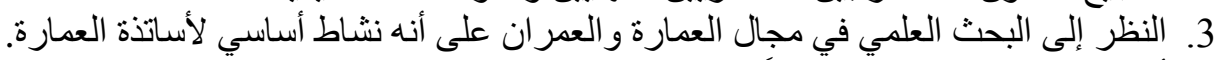

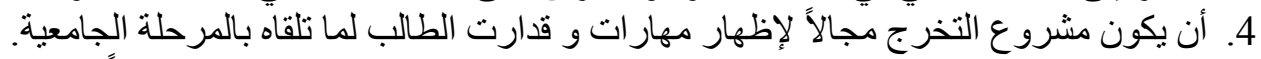

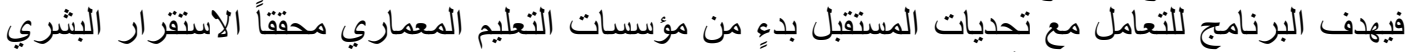

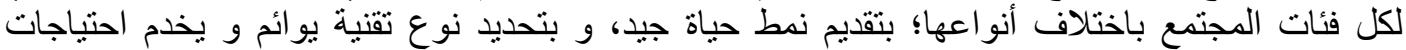

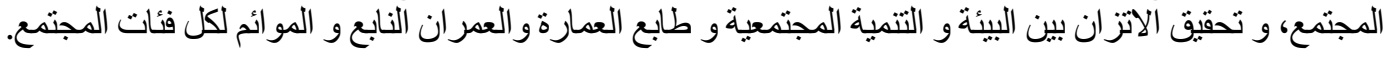

$$
\text { 3.2. المسابقات الدولية لمشروعات التخرج: }
$$

تهدف المسابقات المعمارية لتحفيز المبتكريين و المميزين في المجال على إنتاج أفضل تصاميم و أفكار

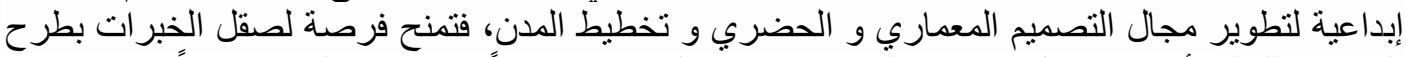

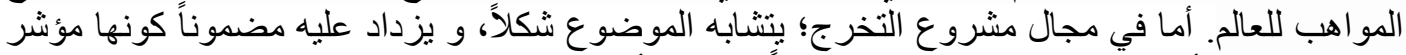

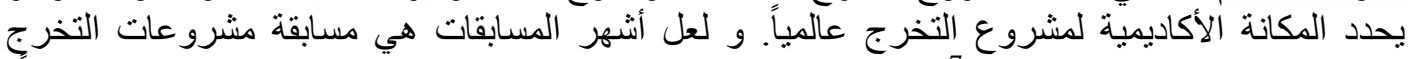

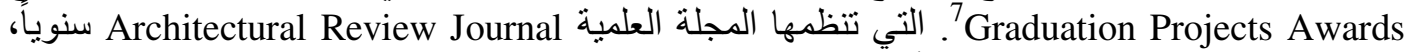

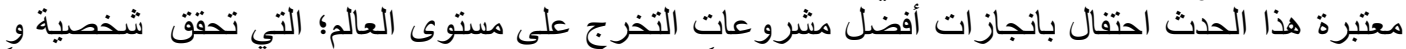

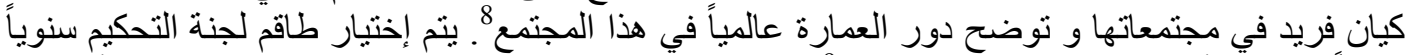

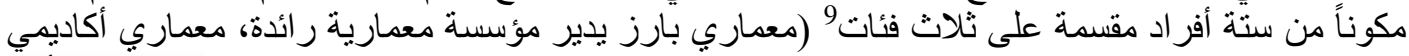

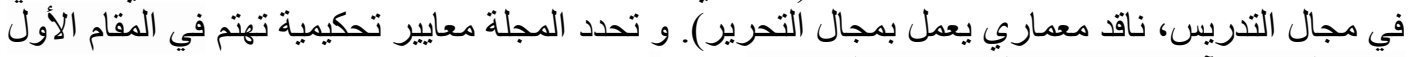

2- معالجة قضية هامة مرتبطة بموقعه.

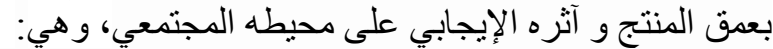

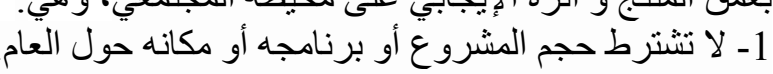

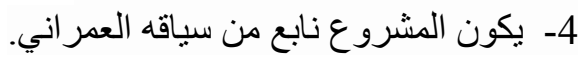

3- يناقش قضايا معمارية و اقعية.

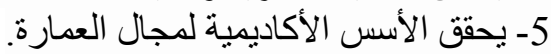

\section{3. تحليل نظام تدريس المحتوى العلمي لمادة مشروع التخرج بالقسم:}

مشروع التخرج هو الخطوة العملية الأخيرة لتؤهل الطالب ليكون خريج، بالتالي فهي تطبيق عملي للمحصلة

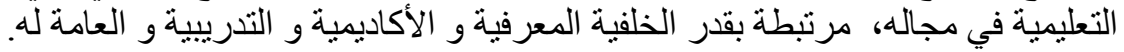

1.3. الحصيلة الدراسية لطالب مشروع التخرج بقسم العمارة :

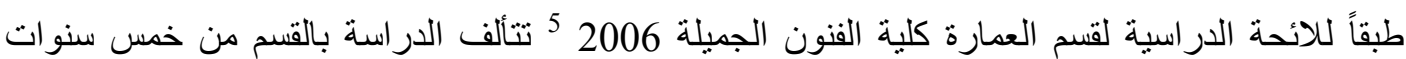
متتالية (تبدأ بسنة إعدادية)، و تتكون الموادة الدية الدارسية من أربع حزم رئيسية (جدول2-الملحق)؛ هي؛ حزمة

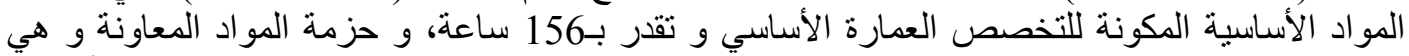

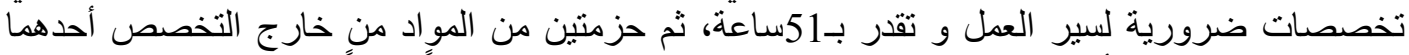

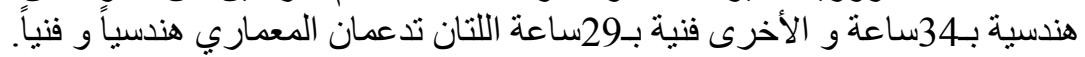

و للوقوف على مستوى قدر الحصيلة الأكاديمية التي يحصل عليها طالب مشروع خلال دراسته الجامعية

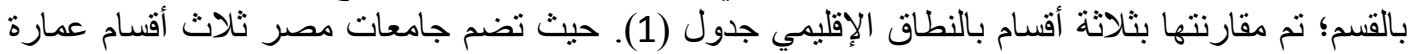
تتبع كليات الفنون الجميلة (حلوان- الإسكندرية- المنيا)، و ما يزية الإفي عن عشرين قسم للهندسة المعمارية تتبع

Journal of Engineering Sciences, Assiut University, Faculty of Engineering, Vol. 41, No. 6, November, 2013,E-mail address: jes@aun.edu.eg 
ولاء السيد يوسف، دراسة مشروع تخرج قسم العمارة كلية الفنون الجميلة جامعة الإسكندرية طبقاً للمعابير الأكاديمية،

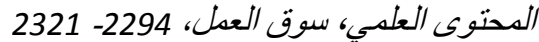

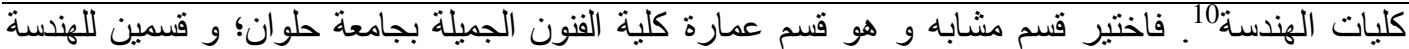
المعمارية أحدهما من نفس الجامعة و الآخر من جامعة القاهرة.

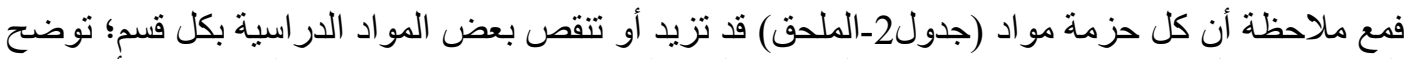

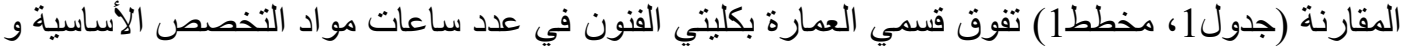

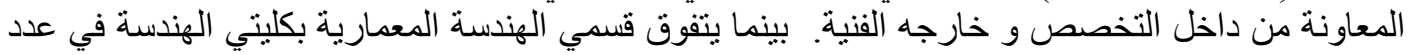

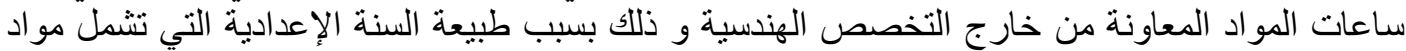

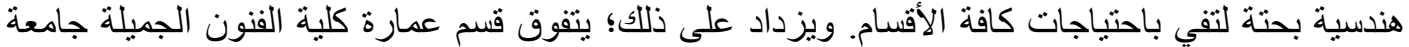

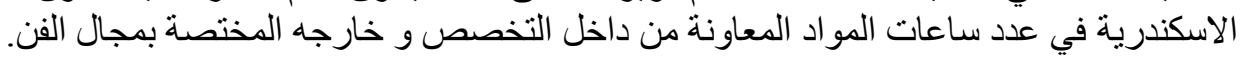

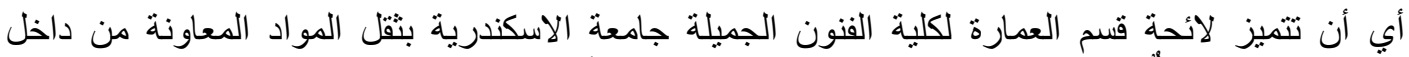

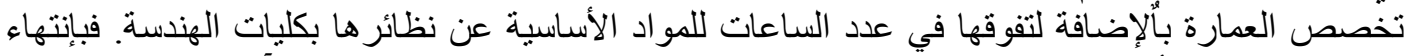

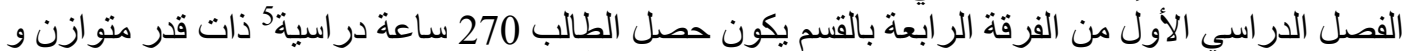

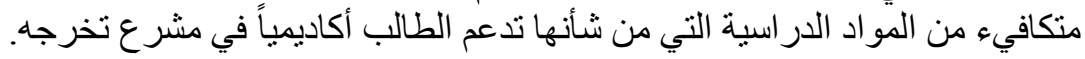
جدول(1): مقارنة لائحة المواد الدرسية لقسم العمارة كلية الفنون الجميلة بنظائره في النطاق الإقليمي للكلية.

\begin{tabular}{|c|c|c|c|c|}
\hline مو اد خارج & مُ مو اد خارج & مو اد معاونة & مو اد & القسم \\
\hline 29 & 34 & 51 & 156 & قسم العمارة، الفنون الجميلة، الإسكندرية \\
\hline 20 & 36 & 50 & 159 & قسم العمارة، الفنون الجميلة، حلوان \\
\hline 8 & 90 & 42 & 130 & قسم الهندسة المعمارية، هندسة، الإسكندرية \\
\hline 10 & 82 & 44 & 134 & قسم الهندسة المعمارية، هندسة، القاهرة \\
\hline
\end{tabular}

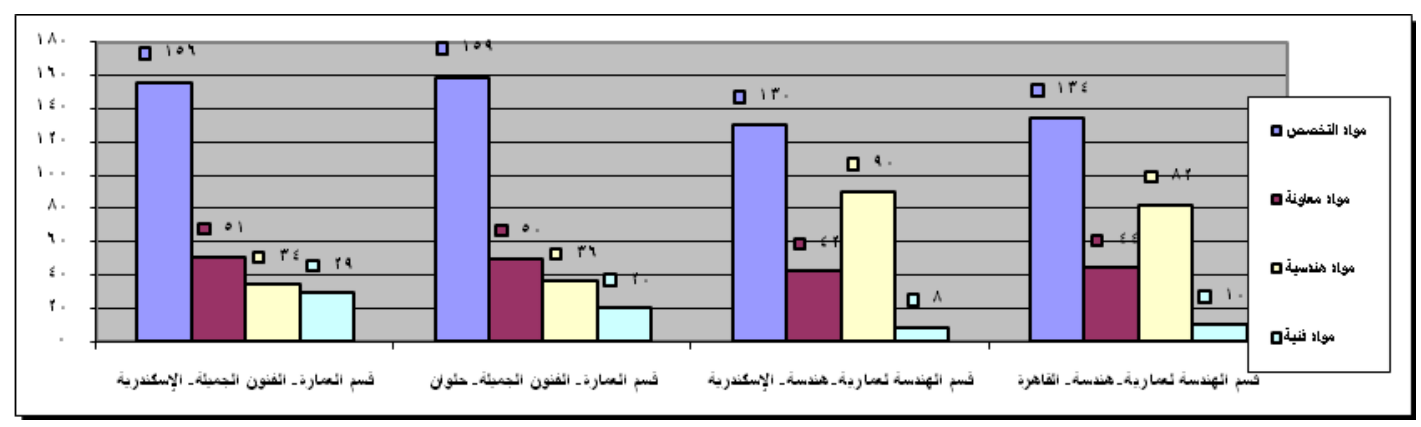

مخطط(1) 11: مقارنة لائحة المواد الدرسية لقسم العمارة كلية الفنون الجميلة بنظائره في النطاق الإقليمي للكلية.

2.3. نظام تدربيس مادة مشروع التخرج بالقسم 112.

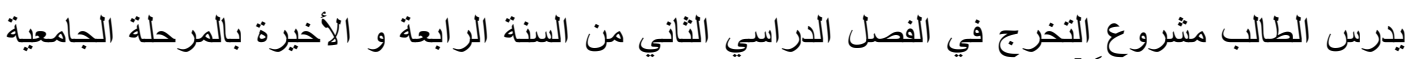

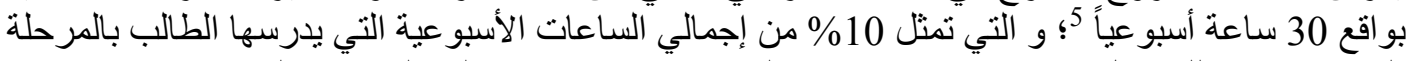

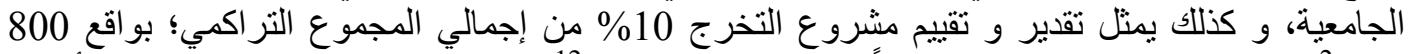

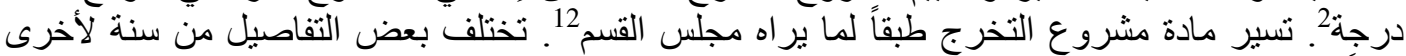

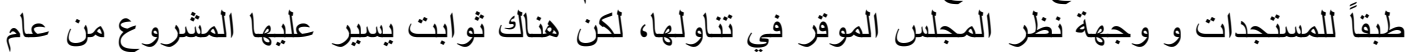

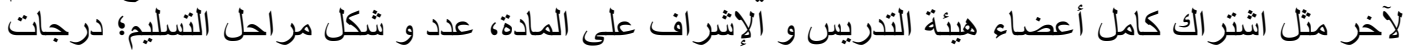

Journal of Engineering Sciences, Assiut University, Faculty of Engineering, Vol. 41, No. 6, November, 2013,E-mail address: jes@aun.edu.eg 
ولاء السبي بوسف، دراسة مشروع تخرج قسم العدارة كلية الفنون الجمبلة جامعة الإسكندرية طبقاً للمعابيير الأكاديبية،

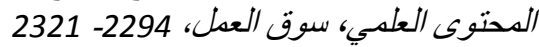

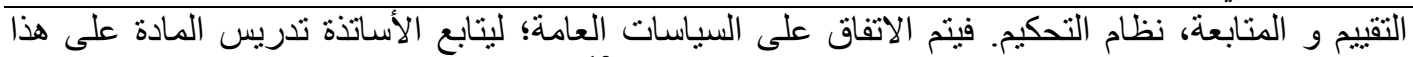

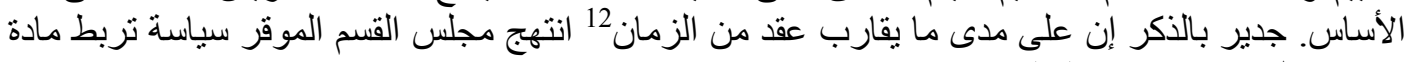
مشروع التخرج بمادة تخطيط مدن.

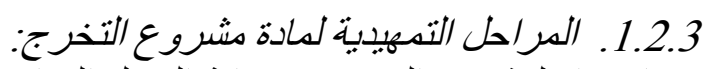

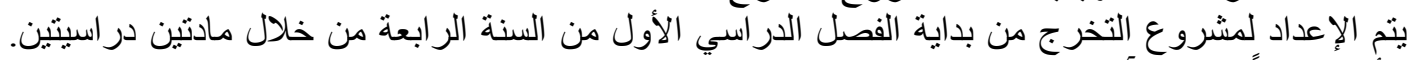

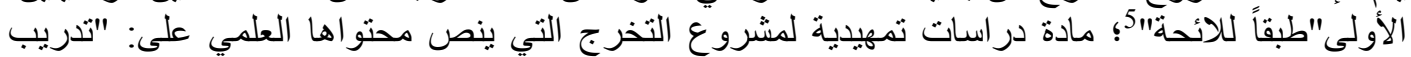

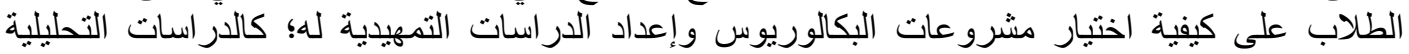

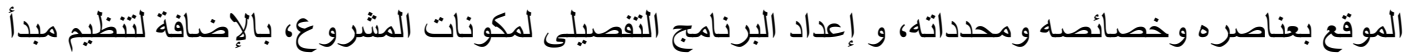

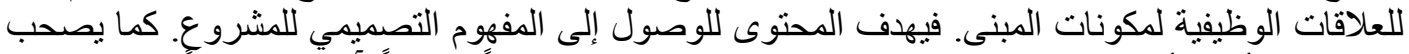

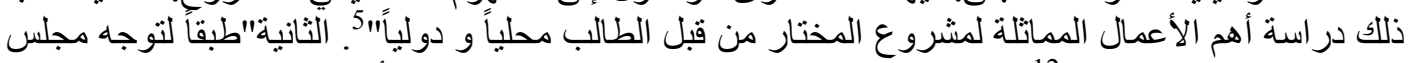

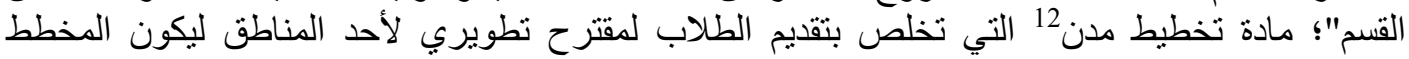

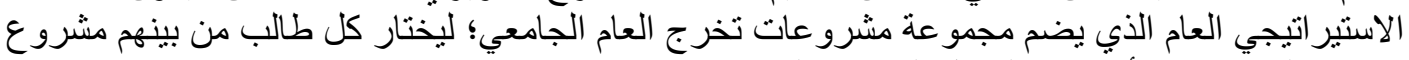
تخرجه الذي سيقوم بأدائه في الفصل الفي الدام الفي الثاني.

$$
\text { 2.2.3. مر /حل سبر مادة مشروع التخرج } 12 .
$$

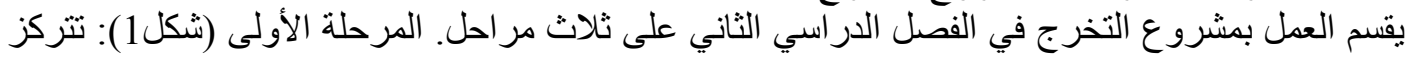

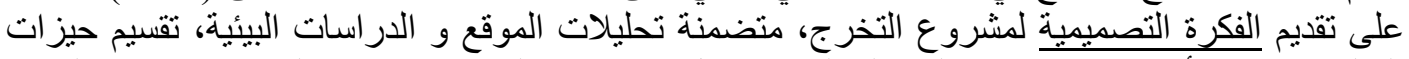

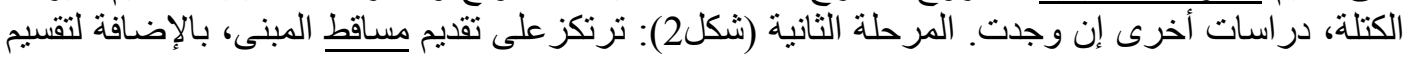

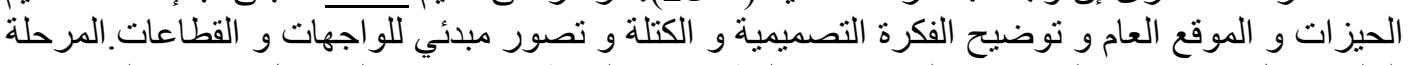

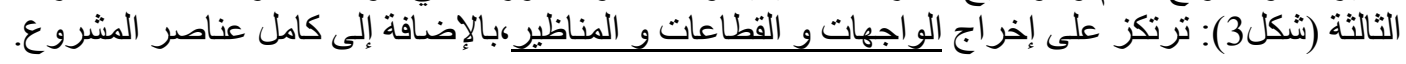

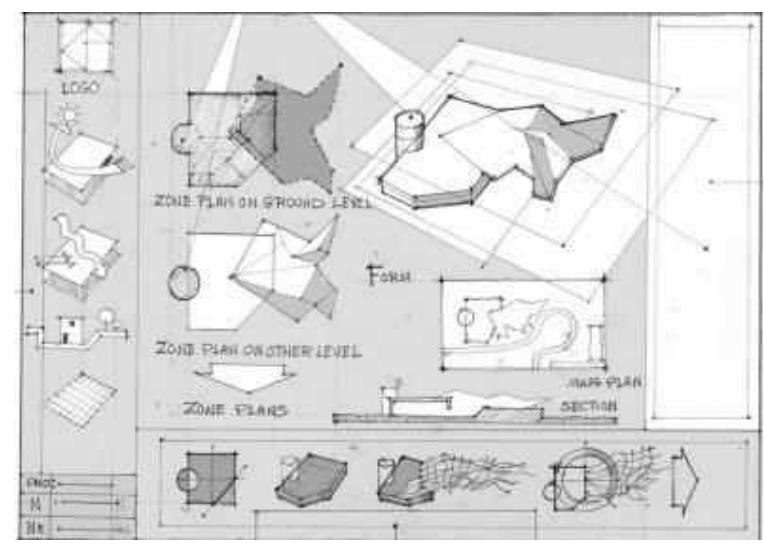

شكل (1) 12: نموذج تقديم المرحلة الأولى.

Journal of Engineering Sciences, Assiut University, Faculty of Engineering, Vol. 41, No. 6, November, 2013,E-mail address: jes@aun.edu.eg 
ولاء السيد يوسف، دراسة مشروع تخرج قسم العمارة كلية الفنون الجميلة جامعة الإسكندرية طبقاً للمعابير الأكاديية،

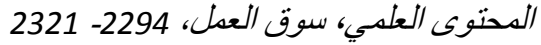

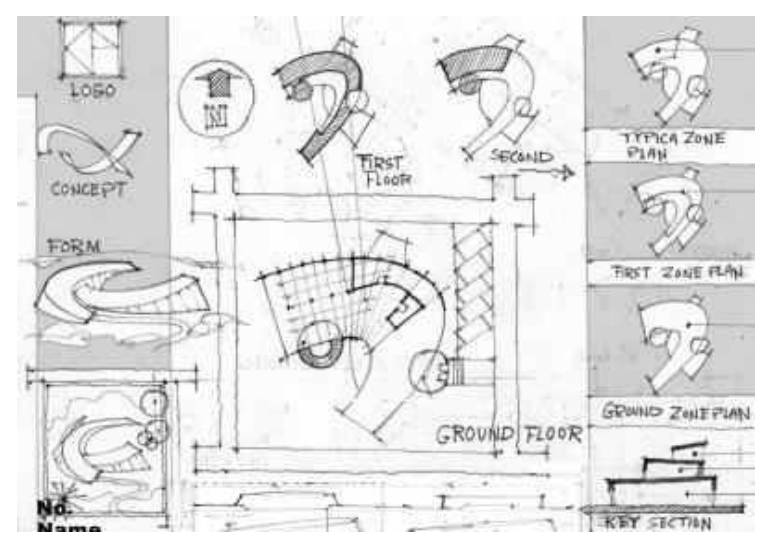

شكل (2)12: نموذج نقديم المرحلة الثانية.

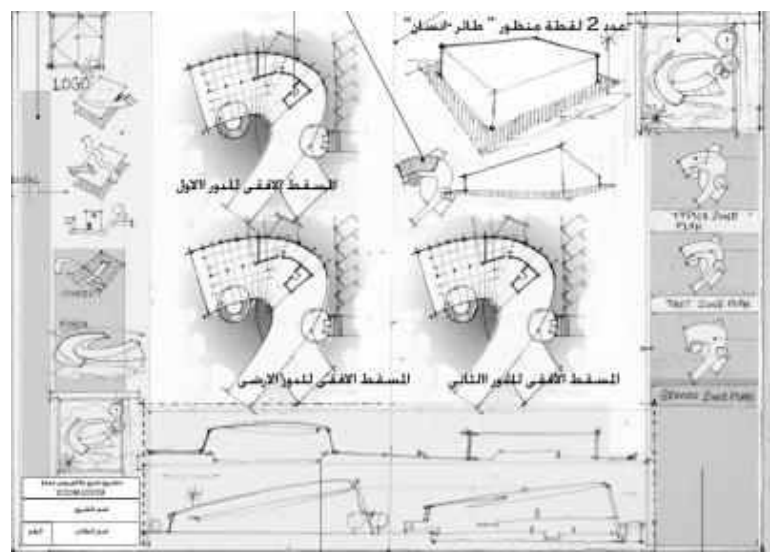

شكل (3) 12: نموذج نقديم المرحلة الثالثة.

يتبع ذلك التسليم النهائي؛ ليتم التحكيم على مرحلتين. الأولى؛ داخلية بواسطة أعضاء هيئة القسم. و الثانية؛

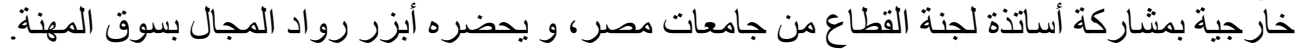
3.3. دراسة تناول الطلاب لمشروعات تخرجهم:

يسخر الطالب نظم التدريس المتاحة أمامه بما ساعده لإبر از إمكانياته. يهدف هذا الثق تقييم مدى تحقيق نظام

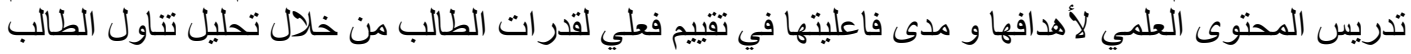

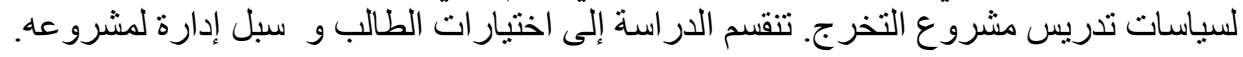

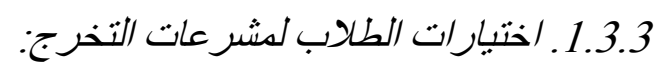

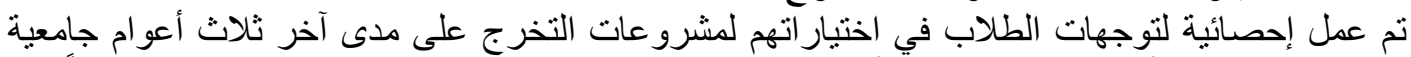

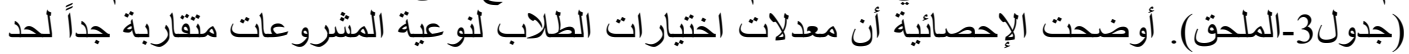

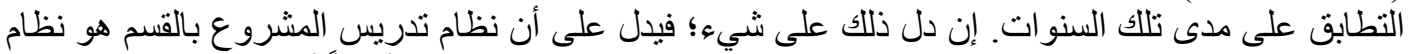

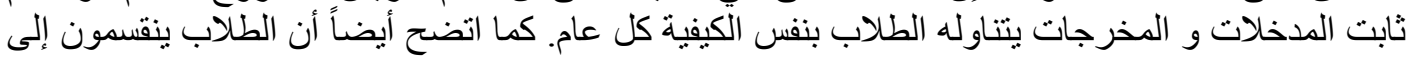

Journal of Engineering Sciences, Assiut University, Faculty of Engineering, Vol. 41, No. 6, November, 2013,E-mail address: jes@aun.edu.eg 
ولاء السيد بيوسف، دراسة مشروع تخرج قسم العمارة كلية الفنون الجمبلة جامعة الإسكندرية طبقًا للمعابير الأكاديية،

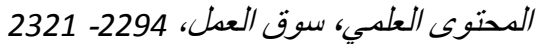

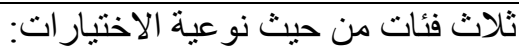

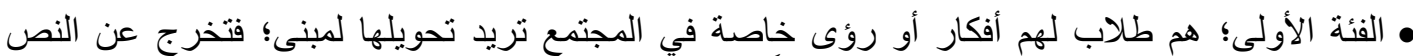

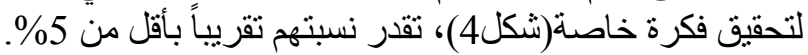
• الفئة الثانية؛ تلجأ لمشروعات تحقيق النظريات كالمستشفيات و المر اكز الثقافية ...الخ (شكل 5)؛ غالباً تريد

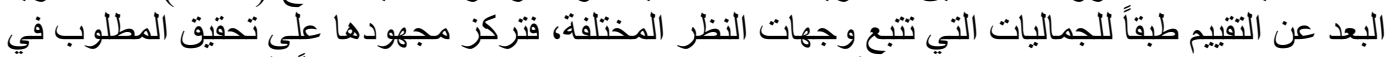

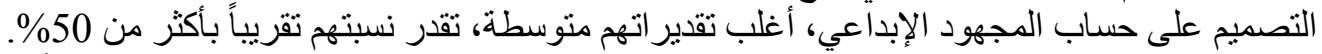

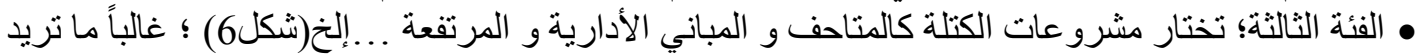

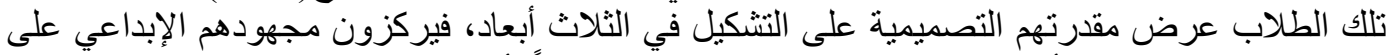

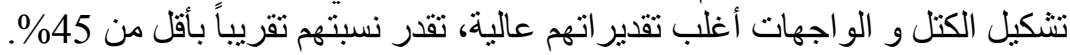

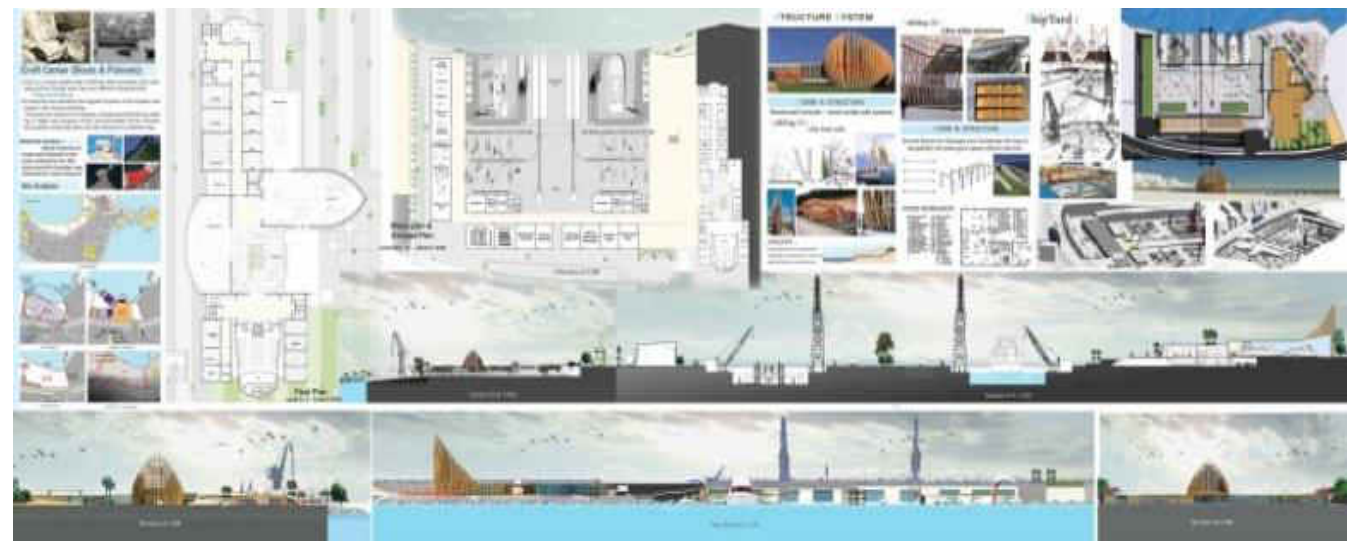

شكل (4) 12: مشروع مركز حرفي للمر اكب و الصيد؛ العام الجامعي 2012-2013 "حاصل على تقدير

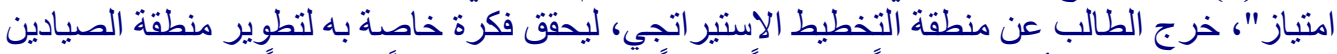

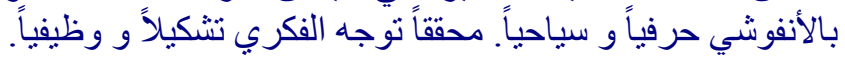

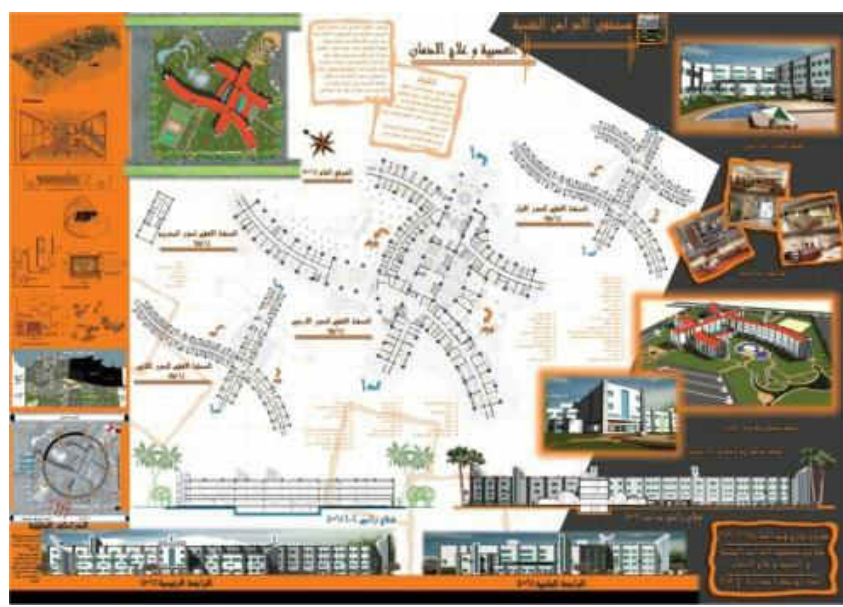

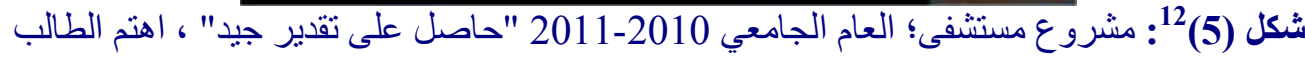
بالمساقط لتحقيق وظيفة الحيز ات، في حين اختزل مجهوده الابداعي في الواجهات و نشكيل الكتل.

Journal of Engineering Sciences, Assiut University, Faculty of Engineering, Vol. 41, No. 6, November, 2013,E-mail address: jes@aun.edu.eg 
ولاء السبي يوسف، دراسة مشروع تخرج قسم العمارة كلبة الفنون الجميلة جامعة الإسكندرية طبقاً للمعابير الأكاديبية، المحتوى العلمي، سوق العهل، 2294- 2321

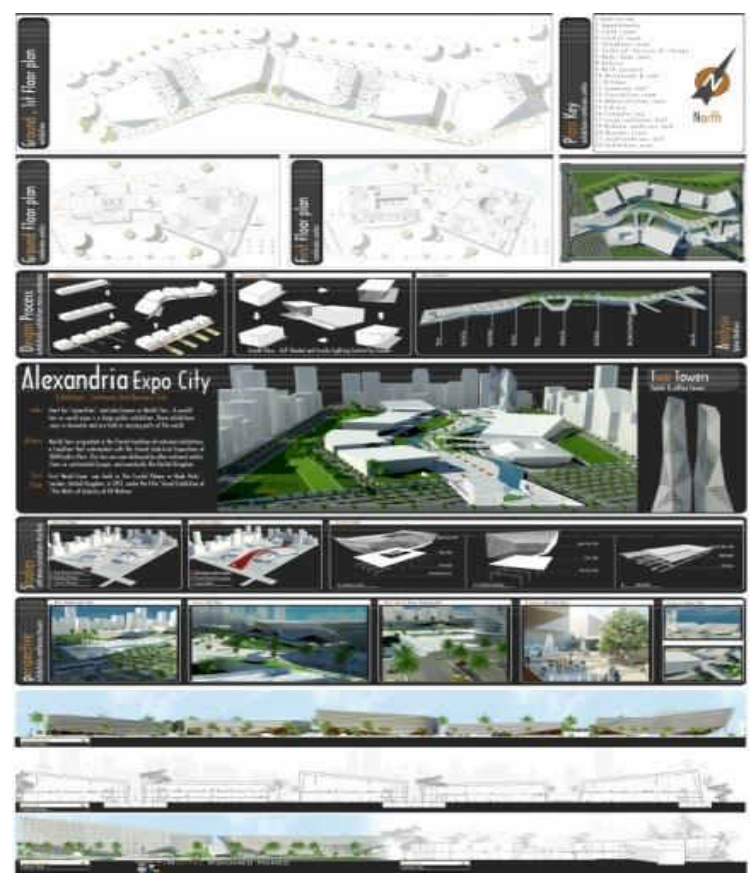

شكل (6)"12: مشروع أرض معارض؛ العام الجامعي 2011-2012 "حاصل على تقدير امتياز"، اهتم الطالب بتشكيل الكتلة لتعبر عن مشرو عاره الذي يمثل رمز للمدينة في مخطط التطوير.

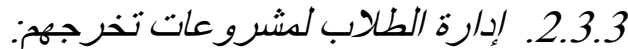
درست إدارة الطالب لمشروع تخرجه من خلال استبيان؛ و ذلك بأخذ عينة عشو ائية من طلاب الفرقة الرابعة الرابة

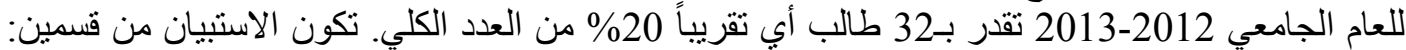

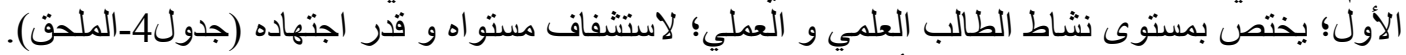

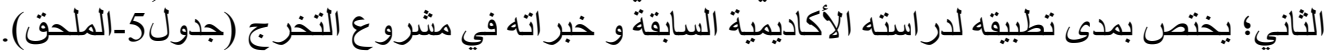
نتائج استبيان متوسط مستوى طلاب مشرو ع التخر جـ (جدول4ـالملحق):

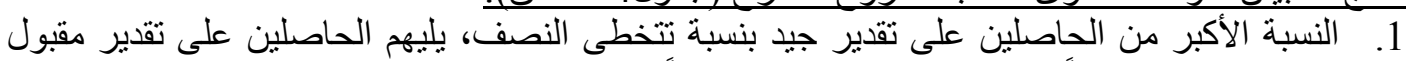

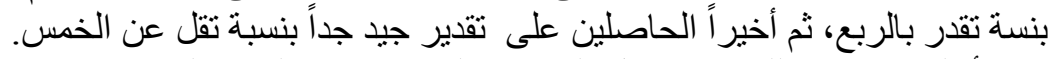

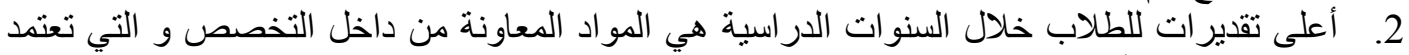

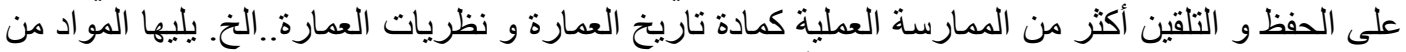

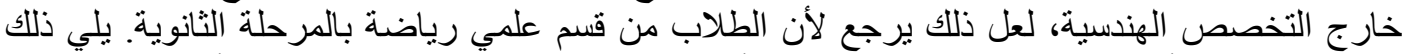

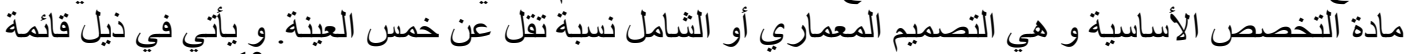

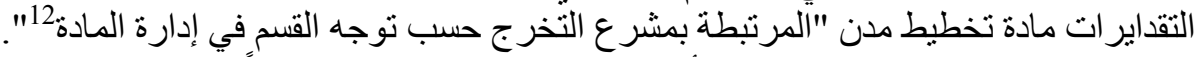

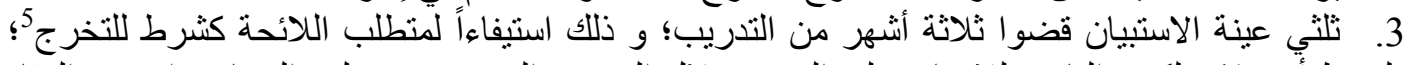

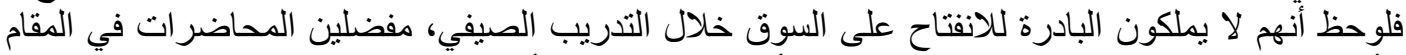

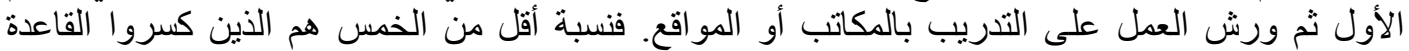
لينفتحوا على مجال العمل "لوحظ في استمار ات الاستبيان أن الطلاب الذين تخطو اثلاثة أثهر من التدريب

Journal of Engineering Sciences, Assiut University, Faculty of Engineering, Vol. 41, No. 6, November, 2013,E-mail address: jes@aun.edu.eg 
ولاء السبي بوسف، دراسة مشروع تخرج قسم العدارة كلية الفنون الجمبلة جامعة الإسكندرية طبقاً للمعابيير الأكاديبية،

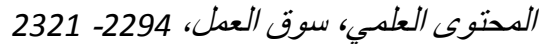

هم الذين تدربو الفي المكاتب و المواقع و وفئ هم الطلاب المتفوقين في مواد التخصص الأساسية". بالتالي قدر

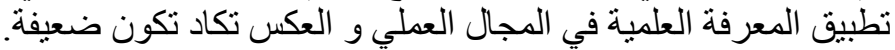

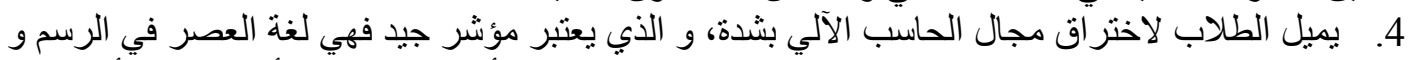

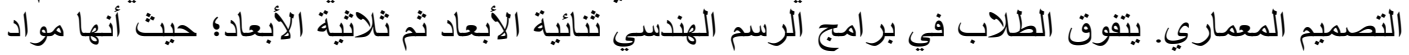

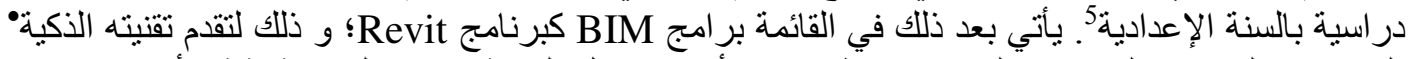

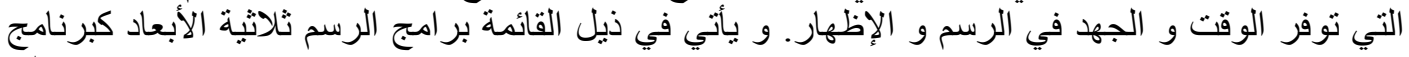

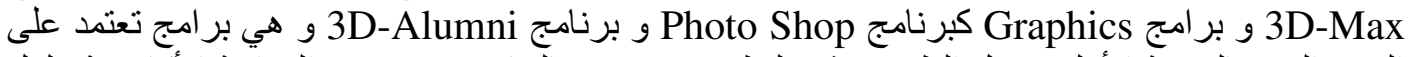

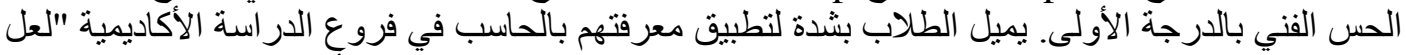

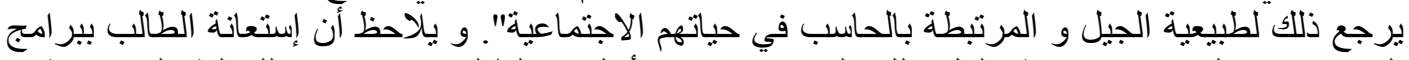

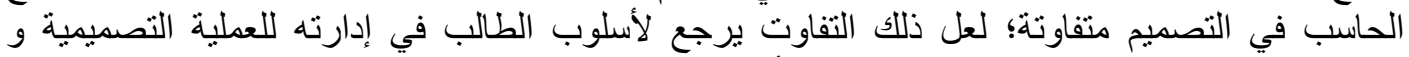

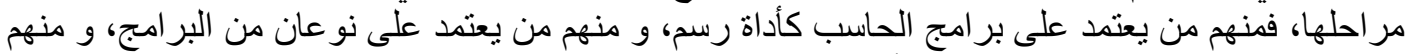

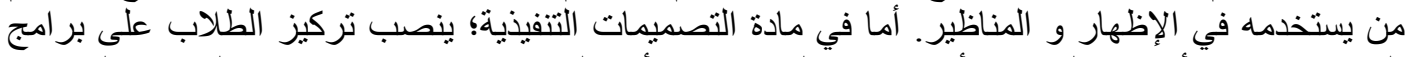

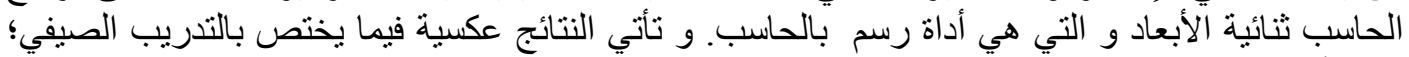

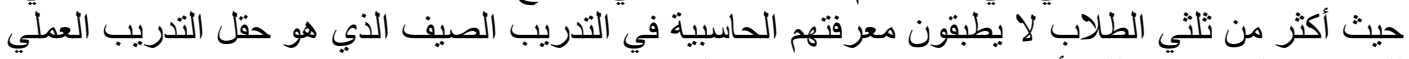

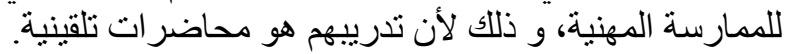

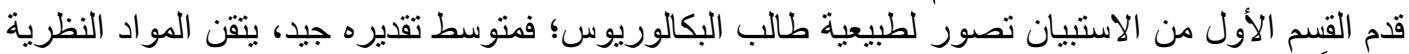

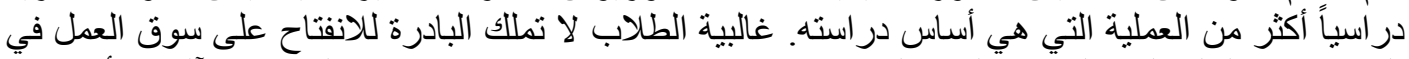

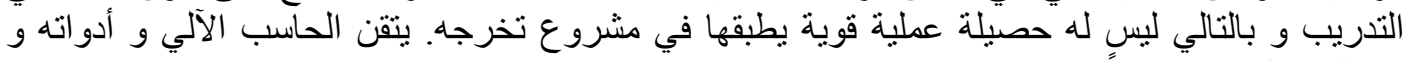
يستطيع تطويعه در اسياً.

نتائج استبيان مدى نطبيق طلاب مشروع التخرج للار اسة الأكاديمية في مشروع التخر جـ (جدول5ــالملحق):

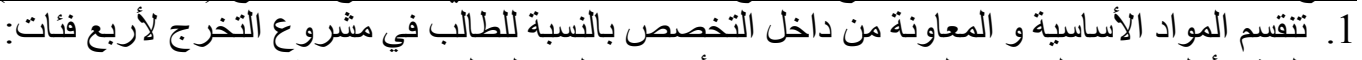

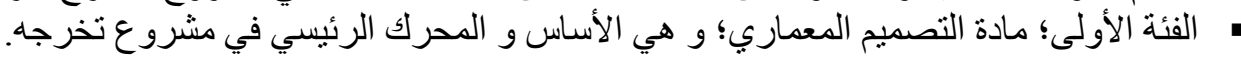

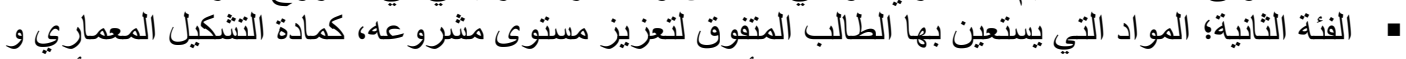

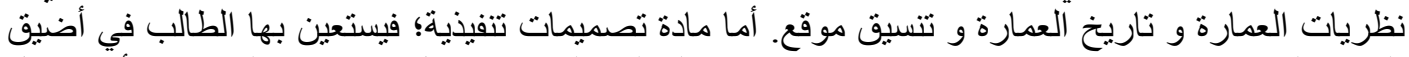

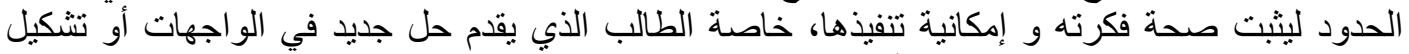

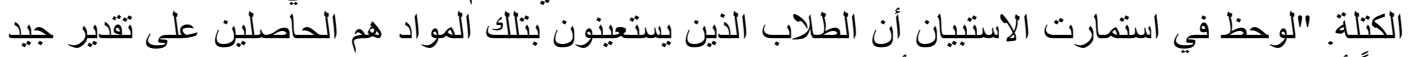

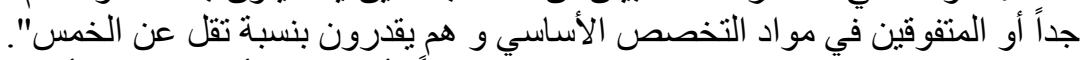

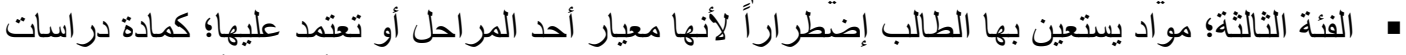

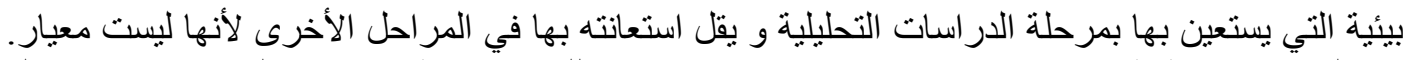

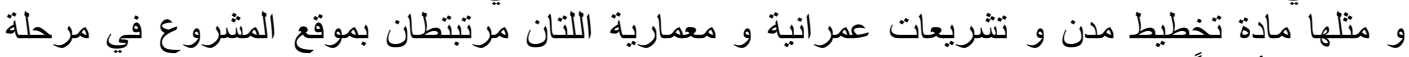
المساقطو أحياناً الو اجهات. • الفئة الربعة؛ مو اد لا يتطرق لهان الوات الطالب من قربيأ بعيد؛ كمادة نظم و إدارة المو اقع ، هندسة مر افق صحية،

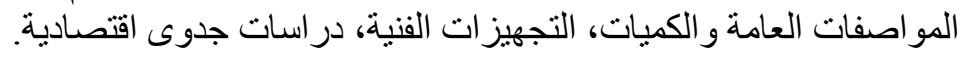
2. تختلف مؤشر ات استخدام الحاسب؛ فالطلاب لديهم بادرة جيدة لاستخدامه؛ خاصة برة بر امج

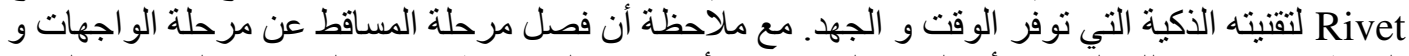

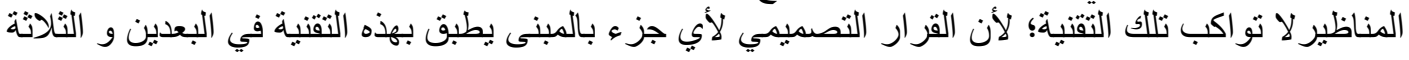

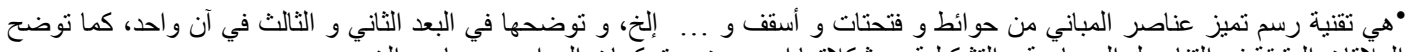

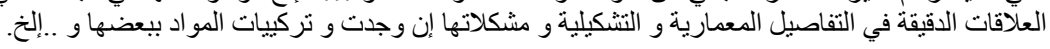

Journal of Engineering Sciences, Assiut University, Faculty of Engineering, Vol. 41, No. 6, November, 2013,E-mail address: jes@aun.edu.eg 
ولاء السبد بوسف، دراسة مشروع تخرج قسم العمارة كلية الفنون الجمبلة جامعة الإسكندرية طبقاً للمعابير الأكاديمية، المحتوى العلمي، سوق العمل، 2294- 2321 في آني و احد. 3. إنغلاق الطلاب على المحاض الماضرات العامة في التدريب الصيفي يجعل الاستفادة منه في مشروع التخرج

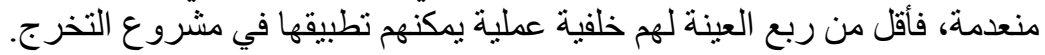

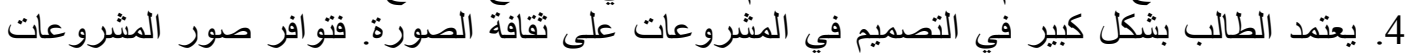

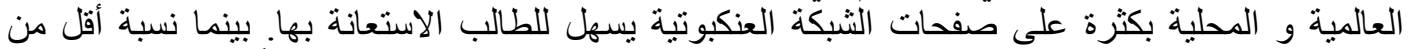

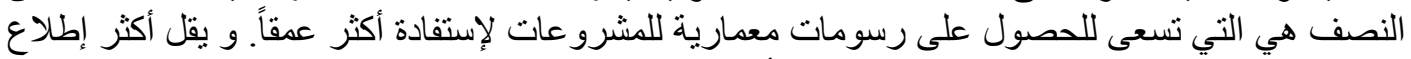
الطلاب على الموضو عات التحليلية و النقدية و الأكاديمية فعشر العينة من يفعل ذلك. لكارية

أوضح القسم الثاني من الاستبيان أن مشروع التخرج بالنسبة للطلاب ما هو إلا مشروع تصميم معماري و الناري

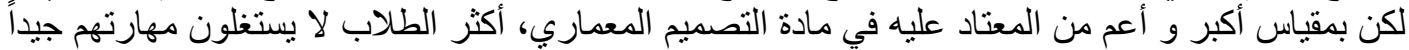

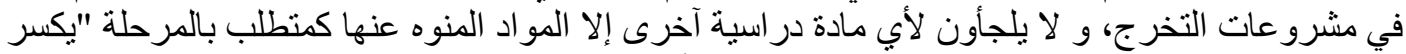

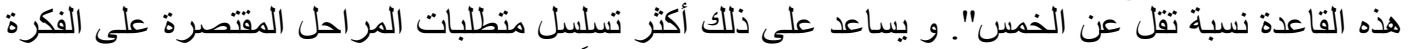

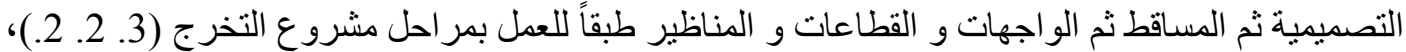

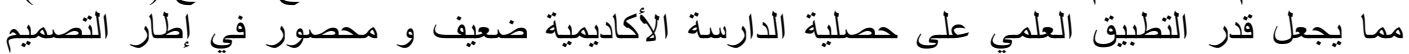
المعماري فقط، مما يعارض كون مشروع التخرج تقييم لقدر استيعاب الطالب لكافة المو اد الدر اسية (1. 3. فئة ).

\section{4. دراسة علاقة مشروع التخرج العمارة بالممارسة المهنية:}

1.4 ـ التعليم المعداري و مدارسة المهنة :

كلمة معماري باللغة الإنجليزية Architecture يرجع أصلها للغة اليونانية، و هي مركسبة من كلمتين (بrchi

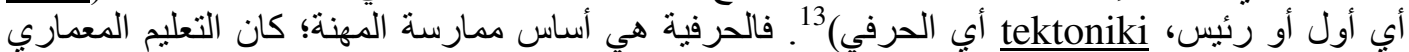

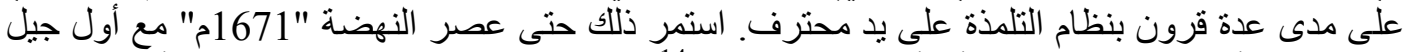

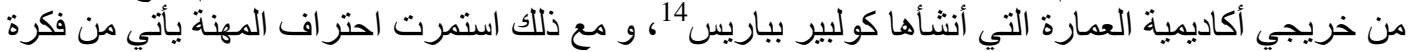

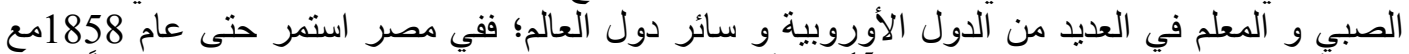

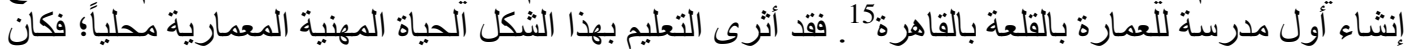

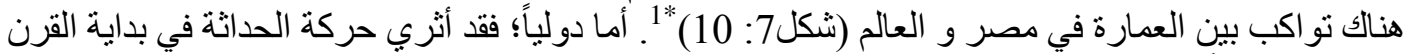

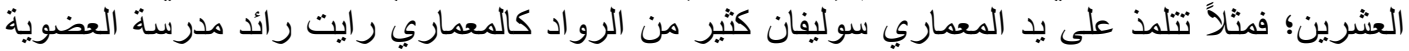

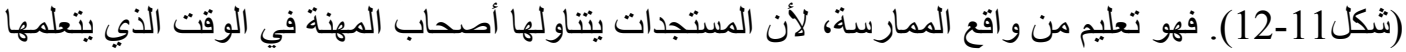

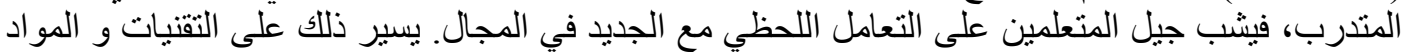

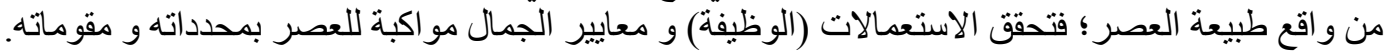

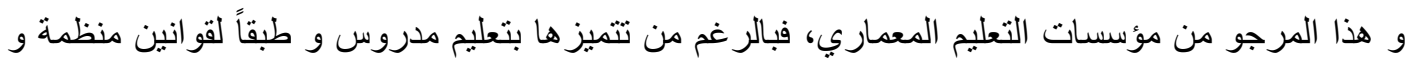

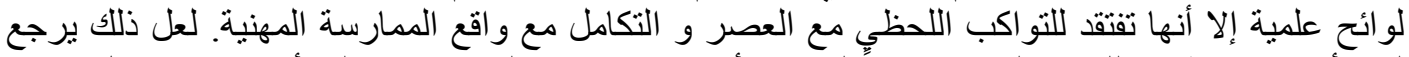

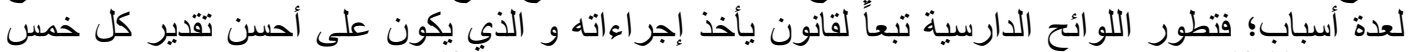

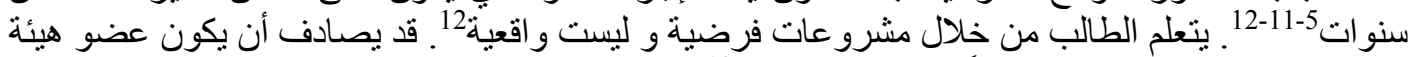

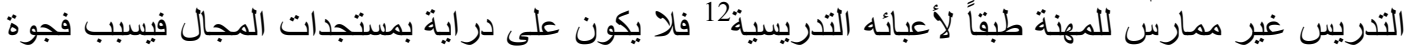

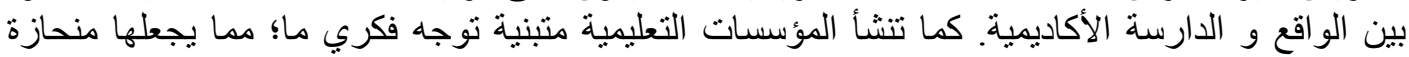

* جدير بالذكر أن أسلوب التعليم وحده ليس السبب في تواكب مستوى العمارة و العمران بين السوق المحلي بمصر و العالم، فقد كان السوق

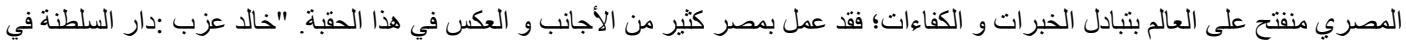

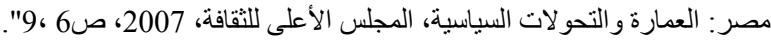

Journal of Engineering Sciences, Assiut University, Faculty of Engineering, Vol. 41, No. 6, November, 2013,E-mail address: jes@aun.edu.eg 
ولاء السيد بوسف، دراسة مشروع تخرج قسم العدارة كلية الفنون الجمبلة جامعة الإسكندرية طبقاً للمعابير الأكاديبية،

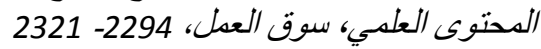
لعامل أو مقوم بعينه " يطابق تخوف سليفان(1.1.)" فيؤثر على الممارسة|-1421 التركية التركيبة المعاصرة للخريج.
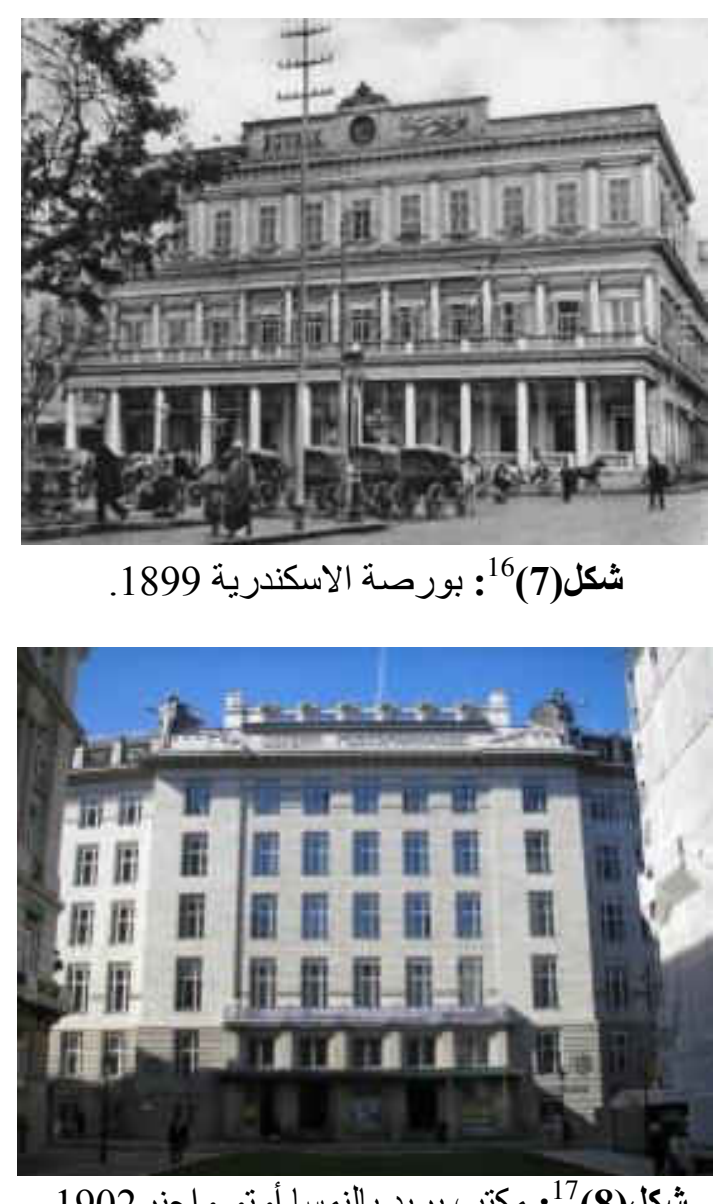

شكل(8) 17: مكتب بريد بالنمسا أوتو و اجنر 1902.

" تو اكب الاتجاه الفكري و التصميمي و تقنيات البناء بأنو اعها بين السوق المحلي و الساحة الدولية لمجال العمارة"

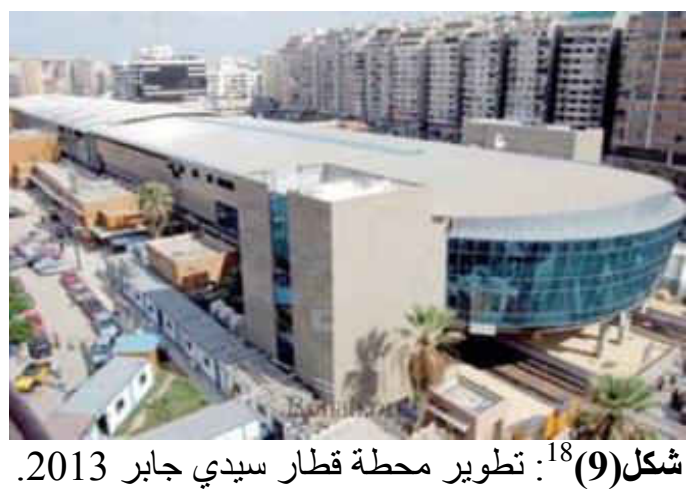

Journal of Engineering Sciences, Assiut University, Faculty of Engineering, Vol. 41, No. 6, November, 2013,E-mail address: jes@aun.edu.eg 
ولاء السيد بيوسف، دراسة مشروع تخرج قسم العمارة كلية الفنون الجميلة جامعة الإسكندرية طبقاً للمعابير الأكاديمية، الدحتوى العلهي، سوق العمل، 2294- 2321 الثند

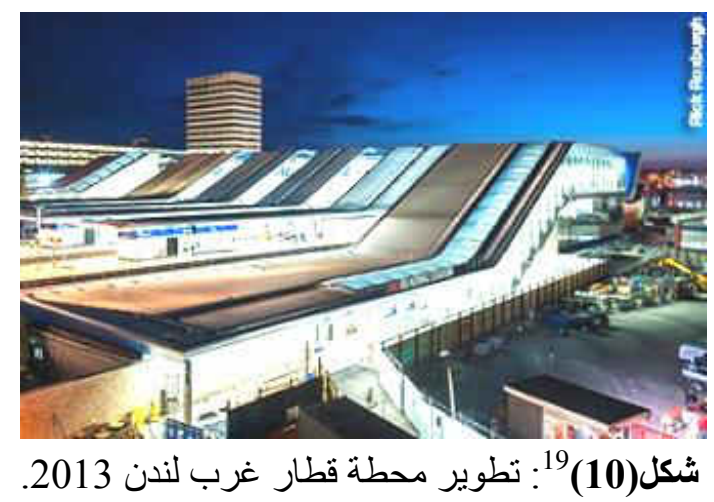

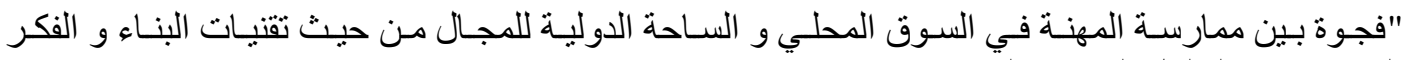
التصميمي و الحلول البيئية و التنفيذ".

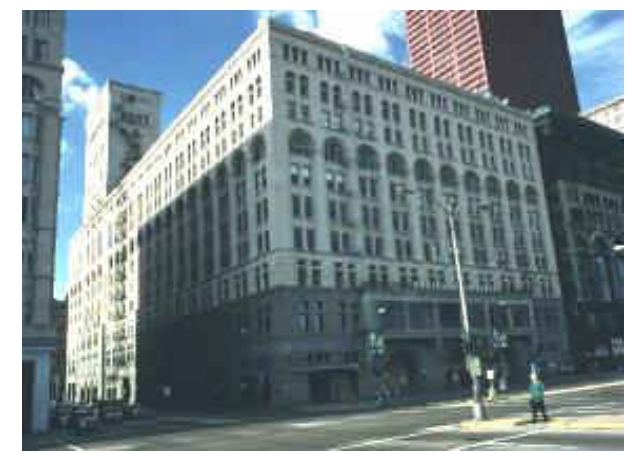

شكل(11) 20: مبنى فان إلين سوليفان أمريكا 1913.

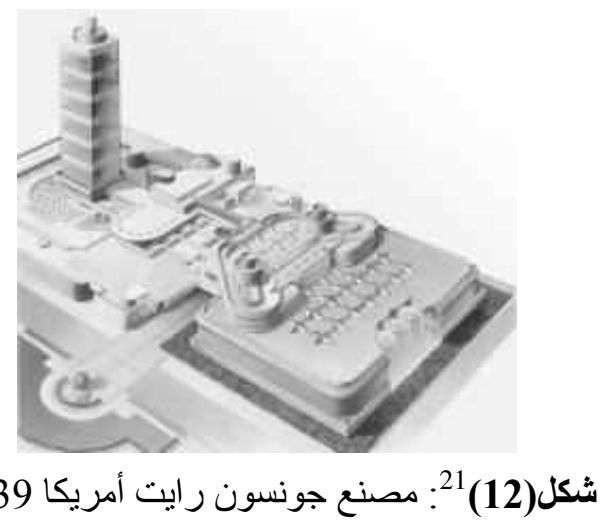

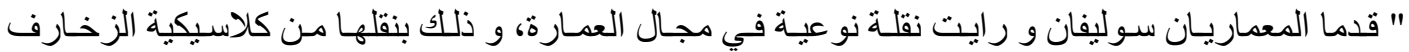

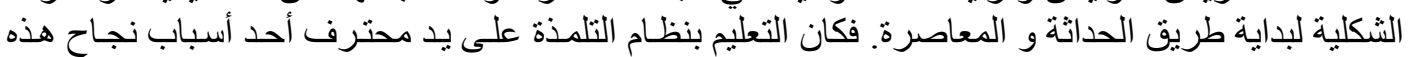

Journal of Engineering Sciences, Assiut University, Faculty of Engineering, Vol. 41, No. 6, November, 2013,E-mail address: jes@aun.edu.eg 
ولاء السبي بوسف، دراسة مشروع تخرج قسم العدارة كلية الفنون الجمبلة جامعة الإسكندرية طبقاً للمعابيير الأكاديبية،

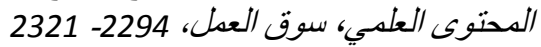

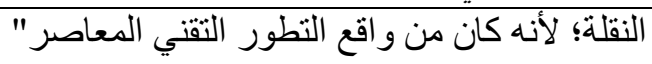
2.4. مجالات العدل بالعدارة في سوق المهنة:

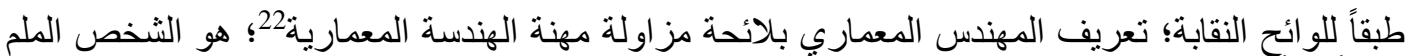

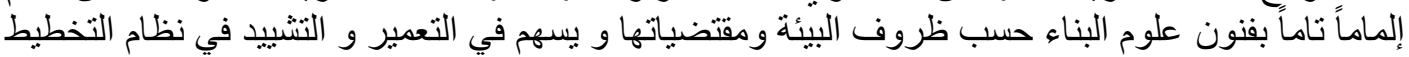

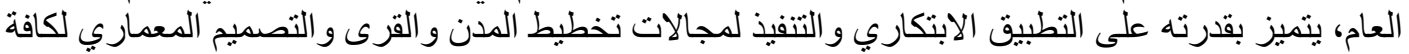

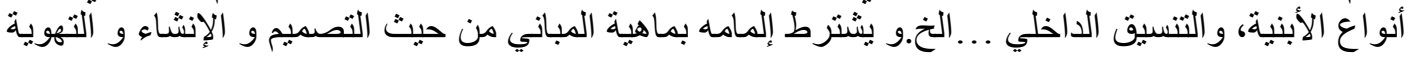

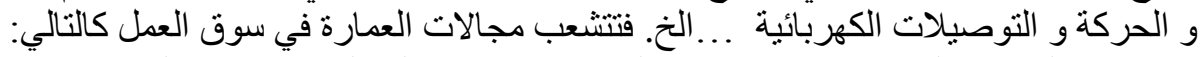

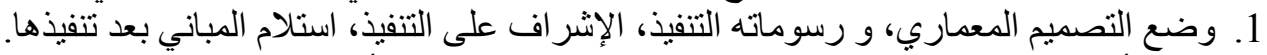

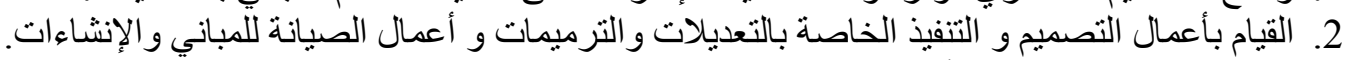

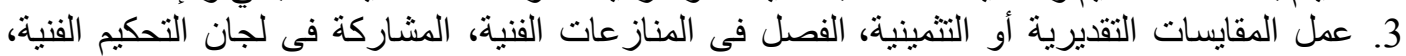

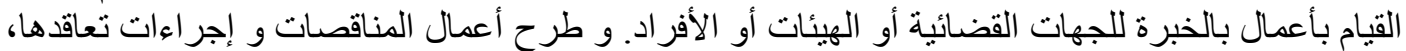

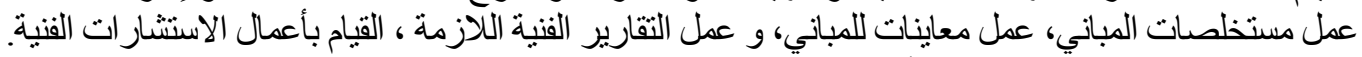
4. تخطيط المدن و القرى، وتقيم أر اضي مشرو عات التئ المباني، وجميع ما يتعلق بالتخطيط العمر اني.

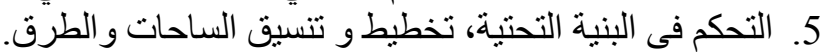

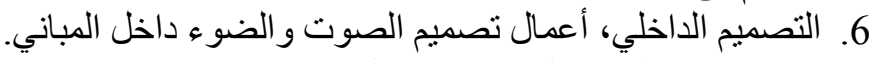
7. تصنيع مو اد البناء و المباني سابقة التجهيز التهيم التهوت.

3.4. دور مشروعات التخرج في إثراء مجالات عمل خريجي القسمفي سوق المهنة: درست علاقة مشروع التخرج بمسار الخريج المهنى و أثره في إثراء كفاءته من خلال استيان ميداني. حيث

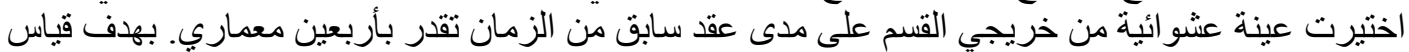

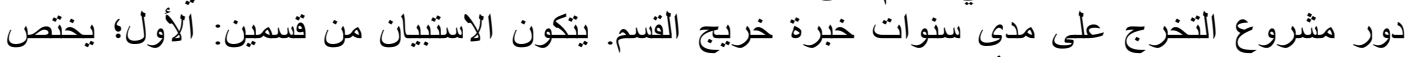

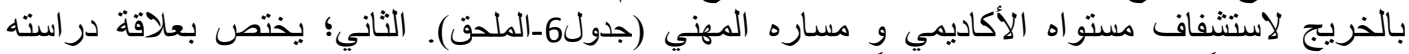

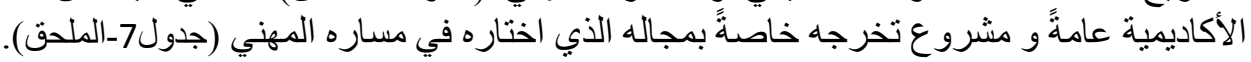

\section{نتائج استبيان مستوى خريجى القسم و مجالات عملهم (جدول6-الملحق) :}

1. تتكون العينة من ذوي مستوى الخبرات المتفاونة طبقاً لسنوات تخرجهم على مدى عقد سابق. كما تشير

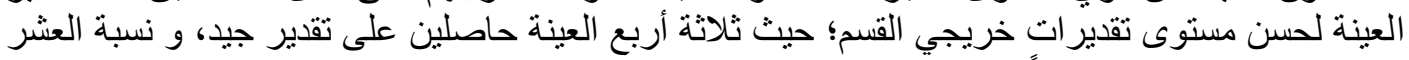

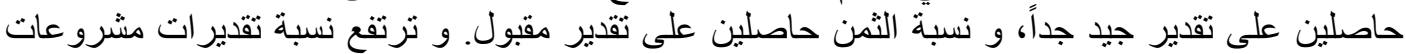

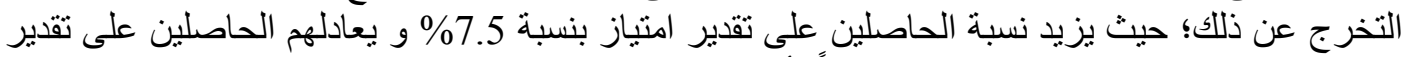

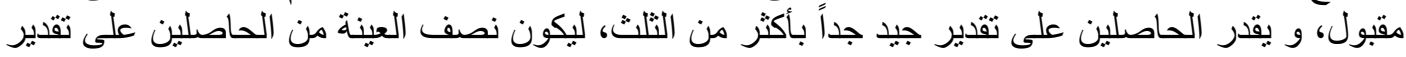

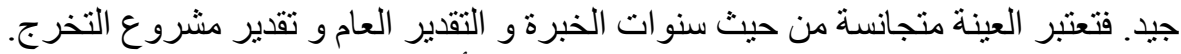
2. تشابه نتائج تفوق الخريجين في المواد الدراسية أثناء در اساته الجامعية مع نتائج الطلاب الفيرة (جدول4الملحق).

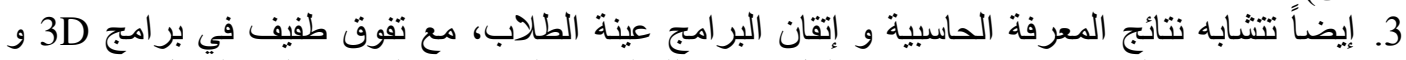

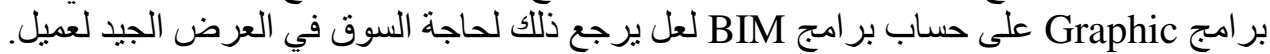

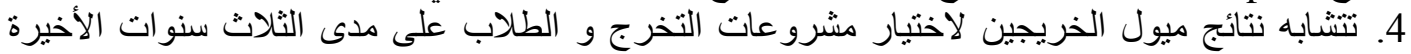

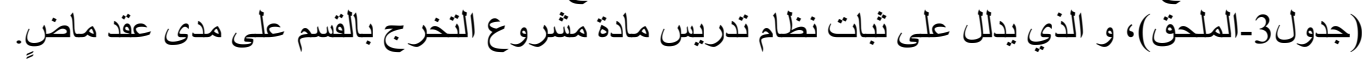

نتائج استييان علاقة الدر اسة الأكاديمية و مشروع التخرج بالمسار المهني لخريجي القسم (جدول4_الملحق):

Journal of Engineering Sciences, Assiut University, Faculty of Engineering, Vol. 41, No. 6, November, 2013,E-mail address: jes@aun.edu.eg 
ولاء السبد بوسف، دراسة مشروع تخرج قسم العمارة كلية الفنون الجمبلة جامعة الإسكندرية طبقاً للمعابير الأكاديمية،

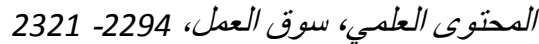

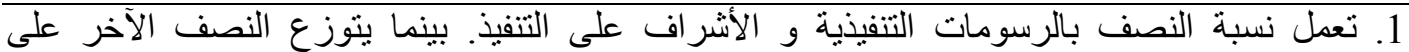

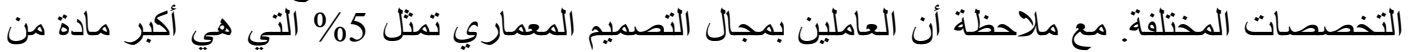

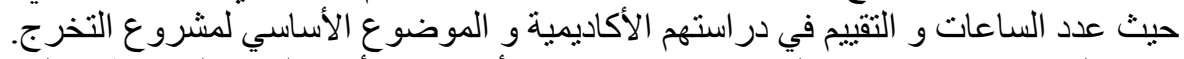

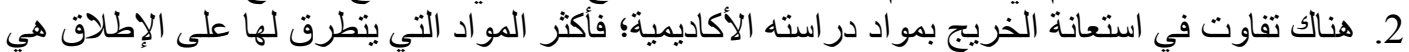

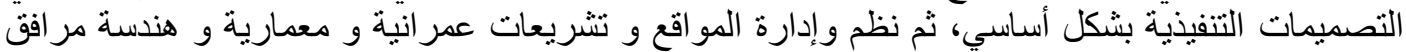

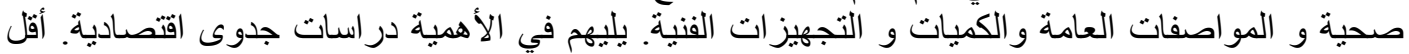

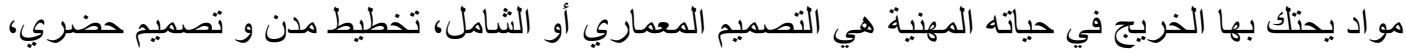

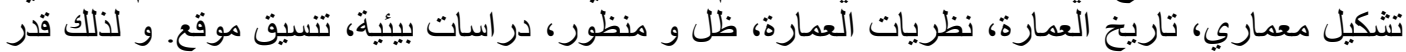

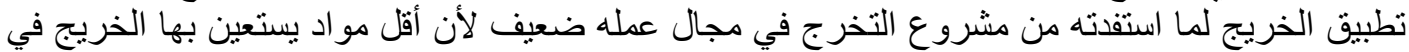

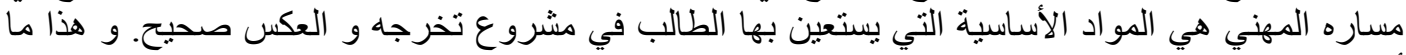
أنشارت إليه النتائج.

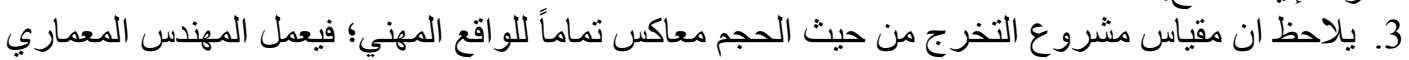

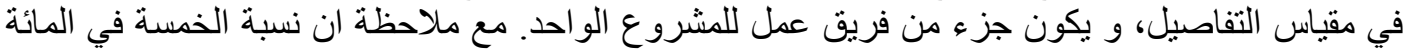
التي عملت في مشرو عات في حجم مشروع التخرج منفردة، كما إنهم يعملون على الفكرة التصميمية فقط. فتتير النتائج لانعدام العلاقة بين مشروع التخرج و مجالات العمل من حيث الكمو الكيف.

\section{5. سبل تطوير مادة مشروع التخرج:}

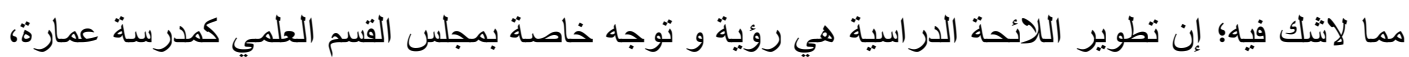

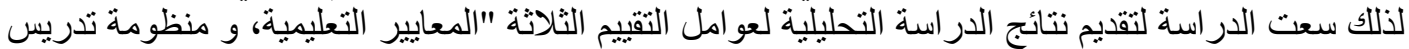

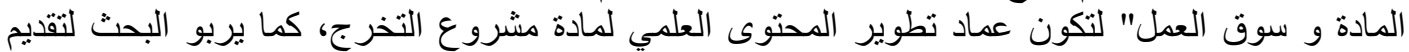
هيكل لتطوير المحتوى العلمي و لمنظومة التدريس من شأنه استيعاب آليات تحقيق النتائج المذكورة.

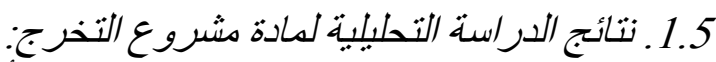

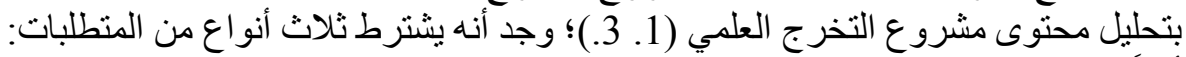

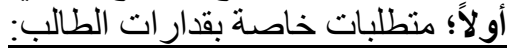
2. بيان مدى استيعاب الطالب لكافة المو اد الدر اسية بالقسم. 1. إظهار و تطوير قدرة الطالب التصميمية.

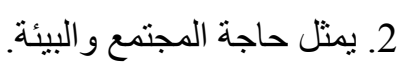

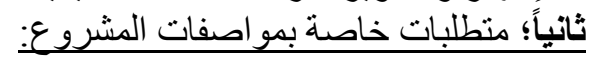
1 ائايكون من المشرو عات ذات الطبيعة الثشاملة و المركبة.

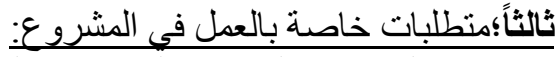
1. إعداد الدر اسات التمهيدية الخاصة بتحلئل التبل الموقع، تحديد الإحتباجات، و إعداد البرنامج المعمارى. 2. يتضمن عناصر توضح إدر اك الطالب لجو انب التخطيط للتصميم المعمارى و تفاصيل المبنى المعمارية.

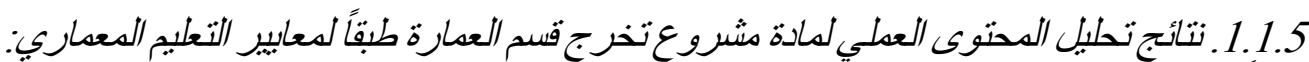

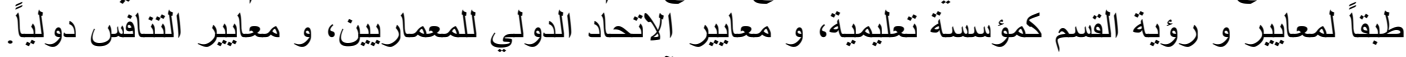

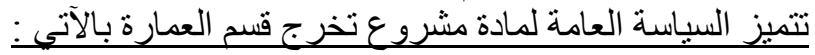

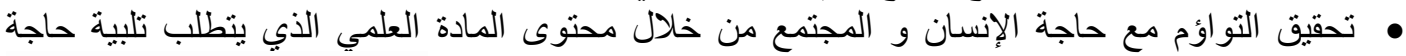

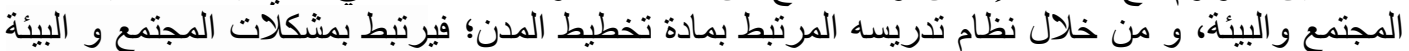

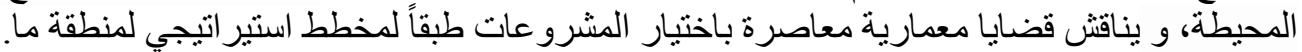

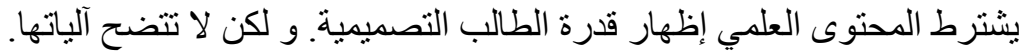

$$
\text { يتم التقييم بنظام التقويم الذاني و الإقليمي على حدٍ سواءٍِ. }
$$

Journal of Engineering Sciences, Assiut University, Faculty of Engineering, Vol. 41, No. 6, November, 2013,E-mail address: jes@aun.edu.eg 
ولاء السيد يوسف، دراسة مشروع تخرج قسم العمارة كلية الفنون الجميلة جامعة الإسكندرية طبقاً للمعابير الأكاديمية،

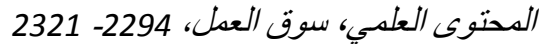

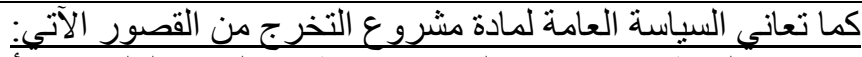

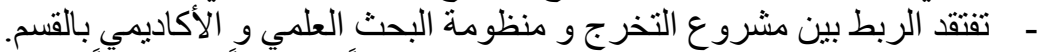
- مثتقد توضيح آليات الرؤية المستدامة للبيئة (إنسانياً و طبيعياً و عمر انياً) مثل:

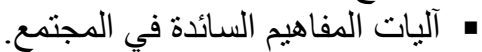

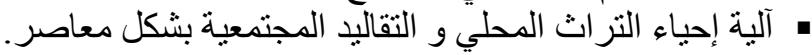
• آليات التقنية المعاصرة الكلائمة لبيئة المكان. • آليات تحقيق الاتزان بين البيئة و التنمية المجتمعية.

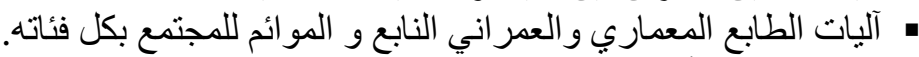

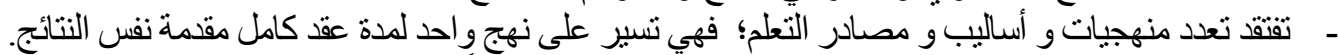

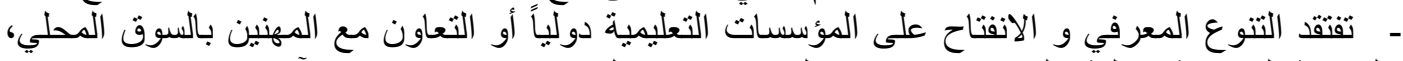

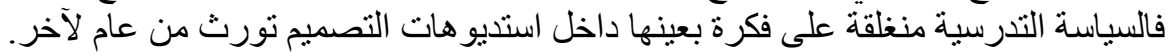

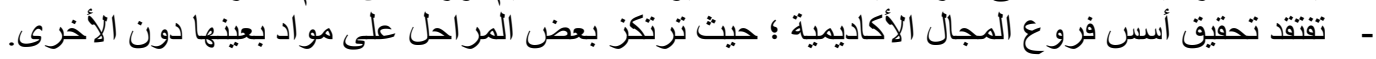

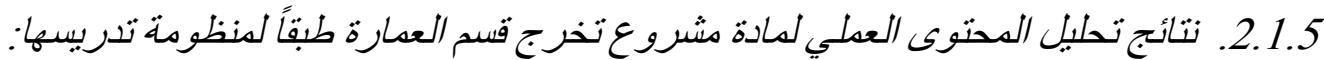

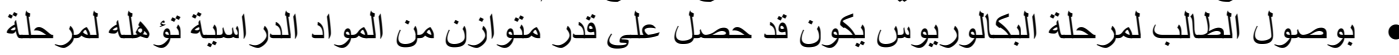

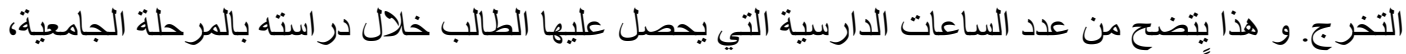

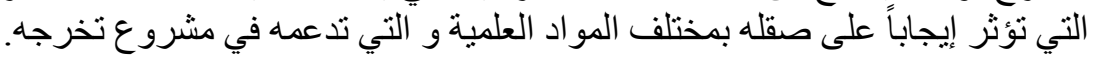

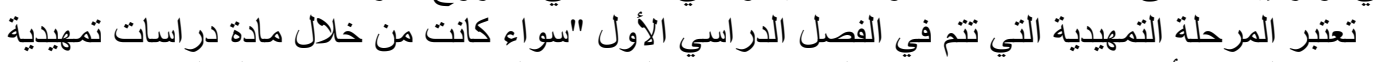

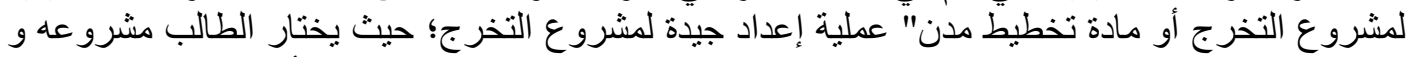

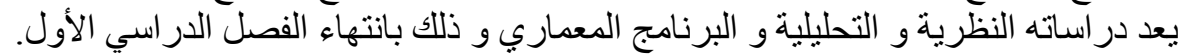

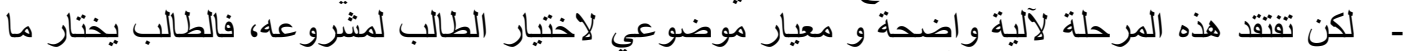

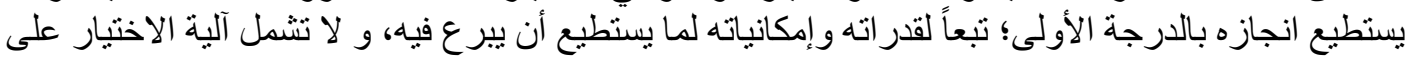

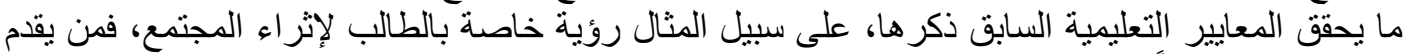

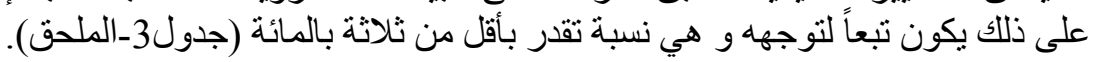
فيما يختص بمر احل المشروع في الفي الفصل الدراسي الثاني:

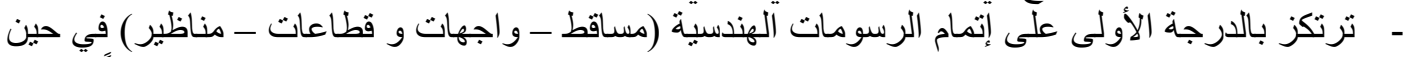

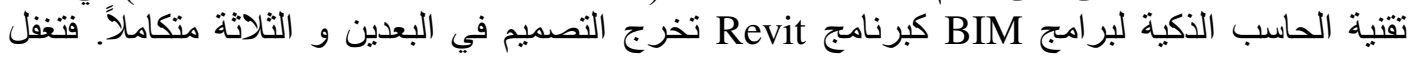

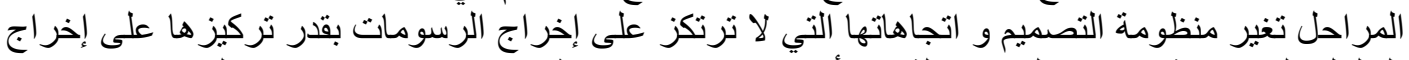

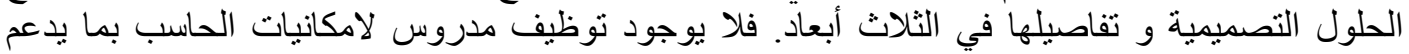
العطلية التصميمية في المشروع.

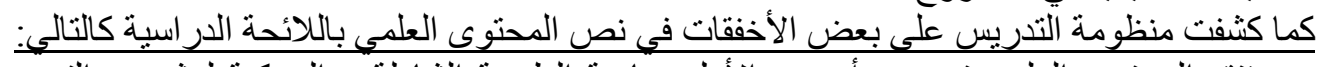

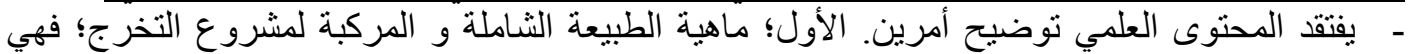

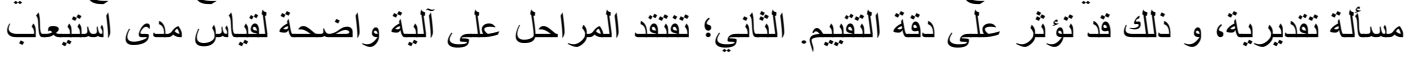

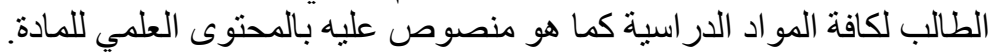

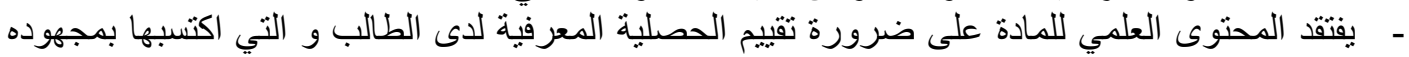

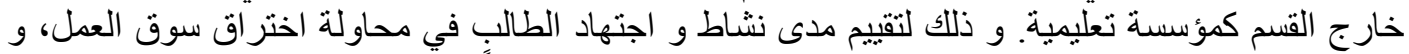

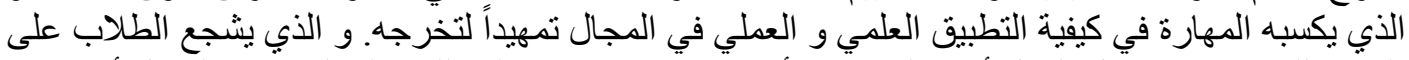

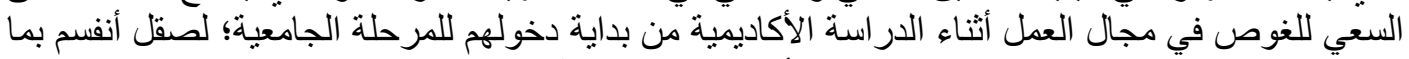

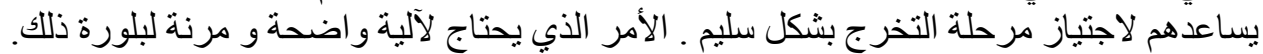

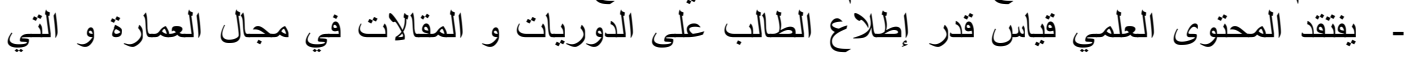

Journal of Engineering Sciences, Assiut University, Faculty of Engineering, Vol. 41, No. 6, November, 2013,E-mail address: jes@aun.edu.eg 
ولاء السيد يوسف، دراسة مشروع تخرج قسم العمارة كلية الفنون الجميلة جامعة الإسكندرية طبقاً للمعايير الأكاديبية،

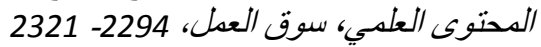

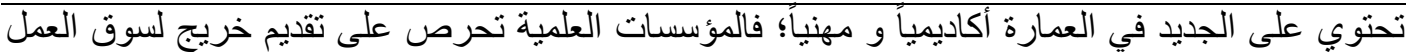

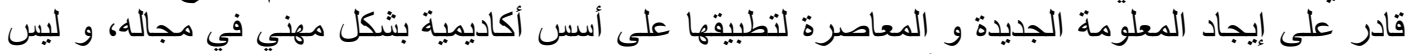

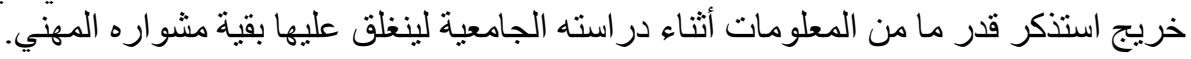

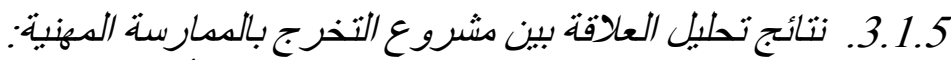

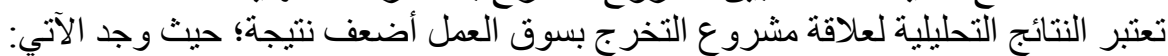

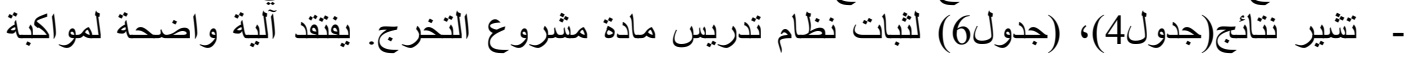

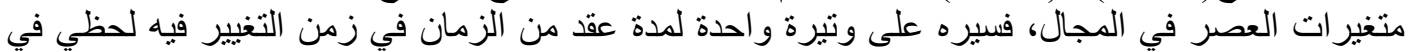

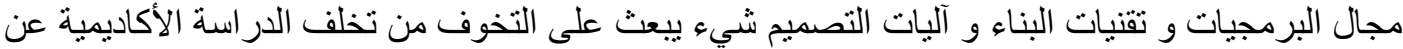

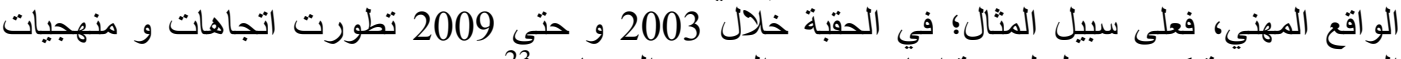

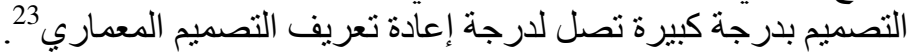

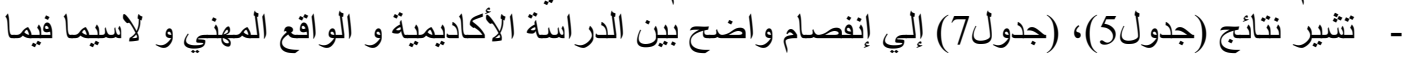

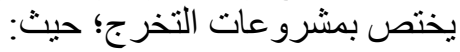

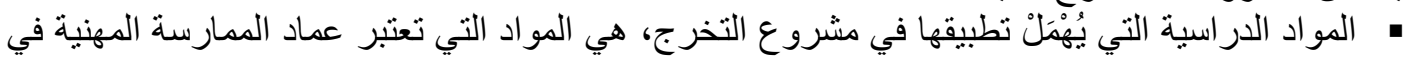

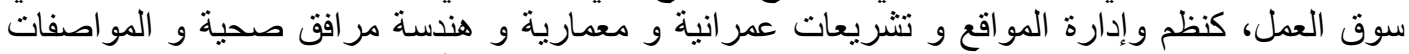

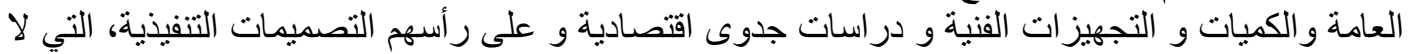

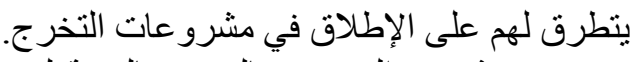

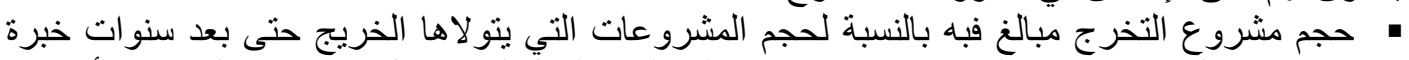

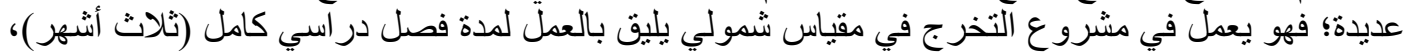

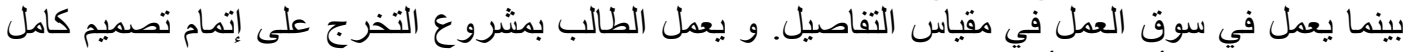

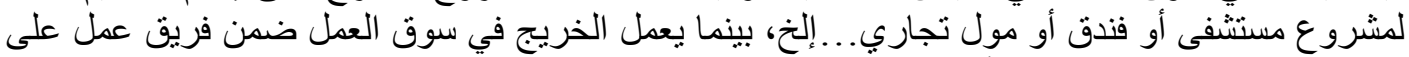

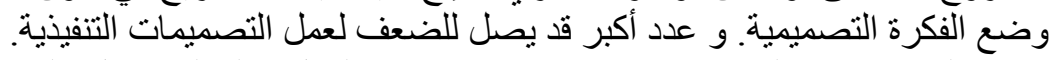

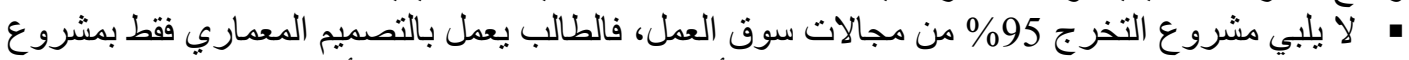

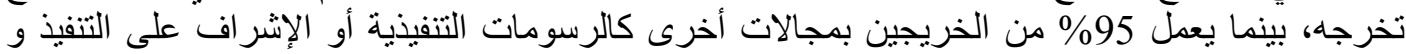

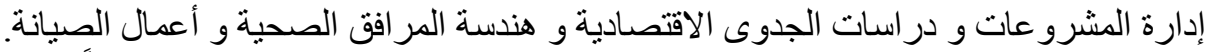

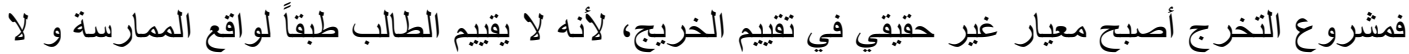

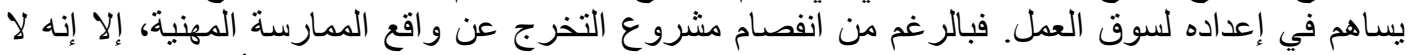

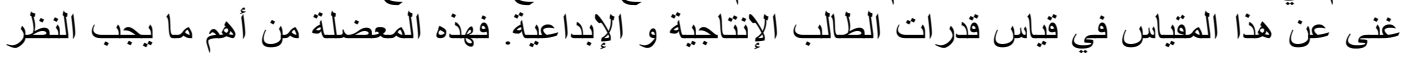

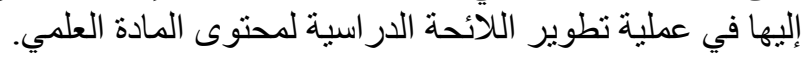

2.5. مقتر ح لهيكل تطوير مادة مشروع تخرج قلسم العمارة:

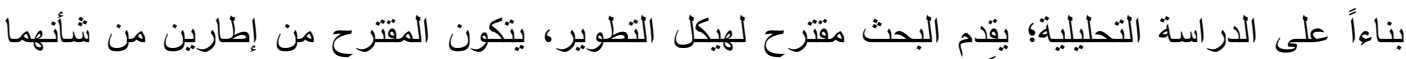

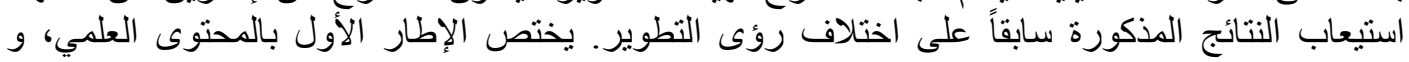
يختص الإطار الثناني بنظام التدريس.

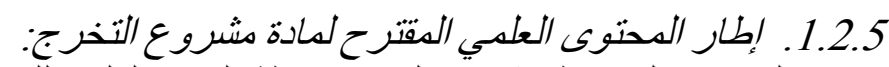

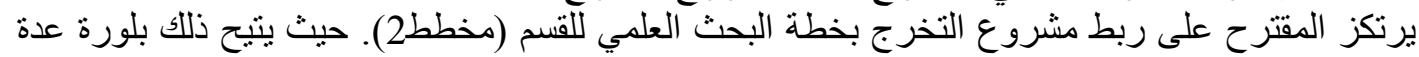

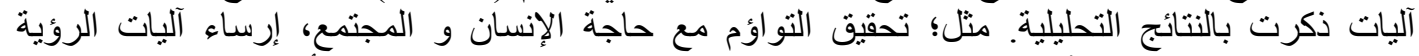

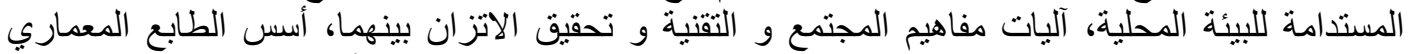

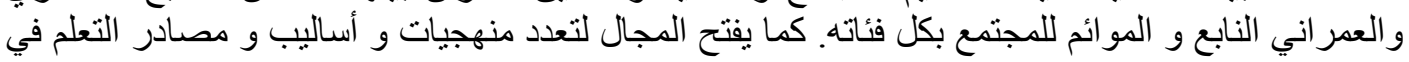

Journal of Engineering Sciences, Assiut University, Faculty of Engineering, Vol. 41, No. 6, November, 2013,E-mail address: jes@aun.edu.eg 
ولاء السيد بوسف، دراسة مشروع تخرج قسم العدارة كلية الفنون الجمبلة جامعة الإسكندرية طبقاً للمعابير الأكاديبية،

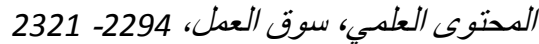

المادة و بالتالي يساعد على تحقيق الأسس الأكاديمية لفروع المقائ المجال. كما تنتوع أساليب التعلم و ذللك بتنوع

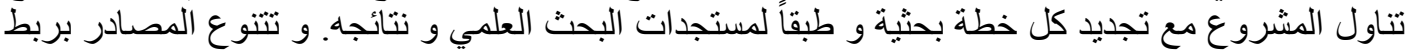

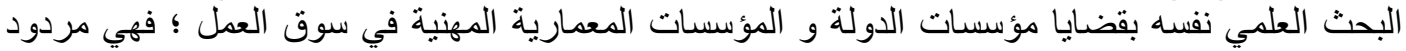

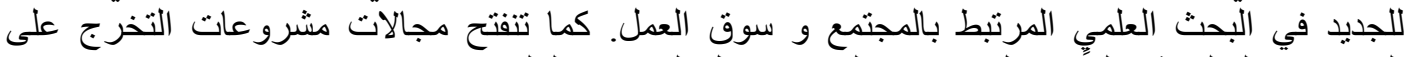

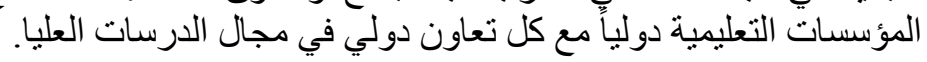

تبنى خطة البحث العلمي على: مثكلات المجتمع القاتمة ـ مثرو عات الدولة التنموية الخاصة بعمران المدن ـ التعلون مع المؤسمات المعمارية و

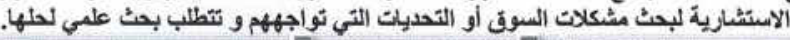

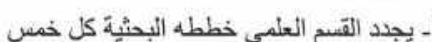

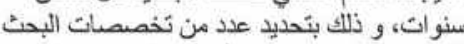

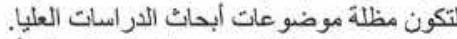

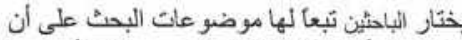

تكون حل أحد مشكلات المجنمع معمارياً أو عمر انباً.

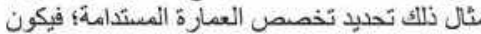

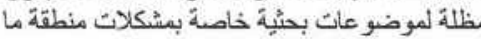

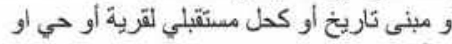

.آ....

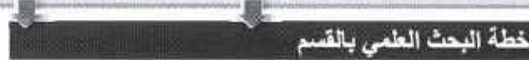

طبقا لخطة البحث العلمي التي توضع لمجالات التخصص بالقتم

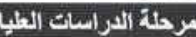

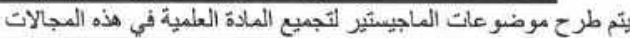

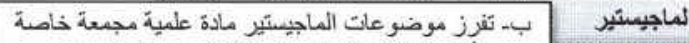

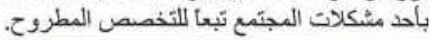

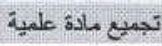

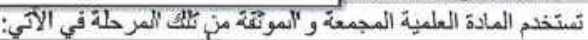

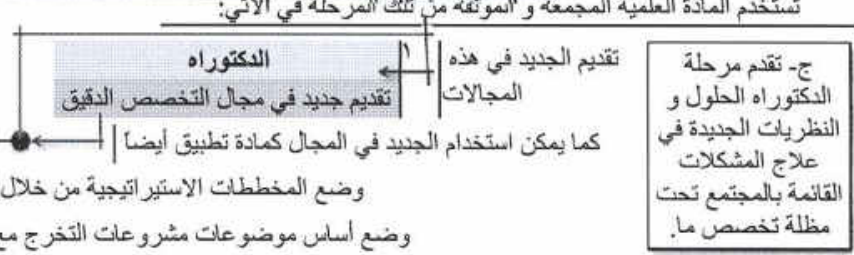

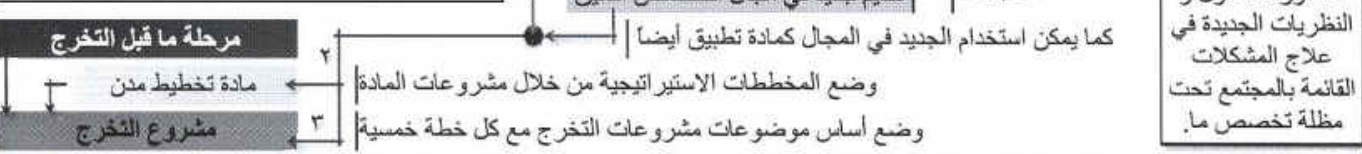

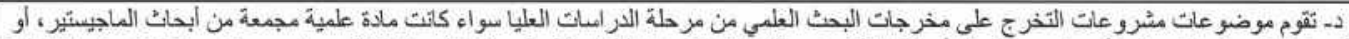

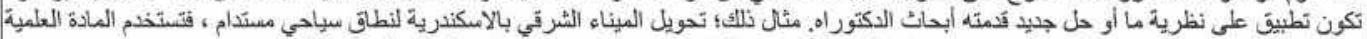

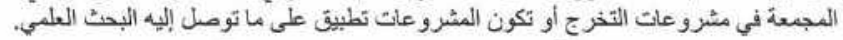

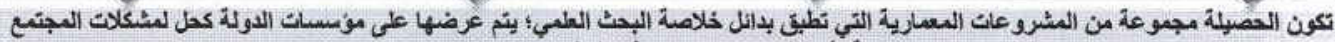

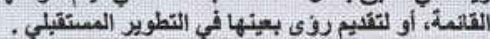

مخطط (2): مقترح الباحث لربط مشروع التخرج بخطة البحث العلمي بالقسم.

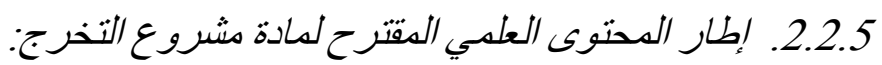

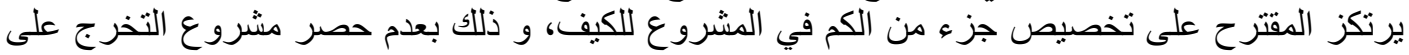

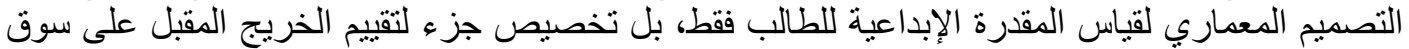

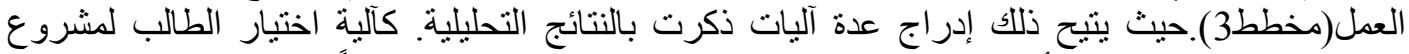

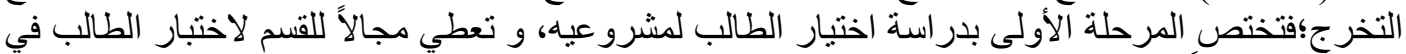

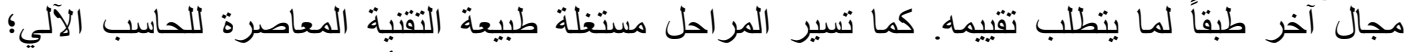
فالمرحلة الثانية تتطلب تقديم رسومات التصميم المعماري ثنائية و ثناثية الأبعاد في آنِ والنية واحد، مما بعزي

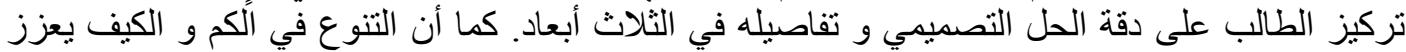

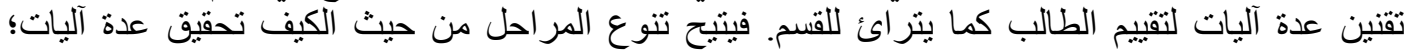
كإمكانية قياس مدى استيعاب الطالب لكافة المو اد الدراسية كما هو منصوص الفئ عليه بالمحتوى العلمي للفي للمادة،

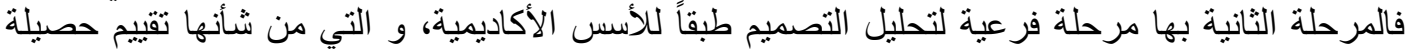

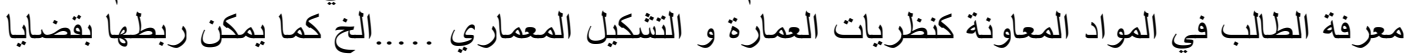

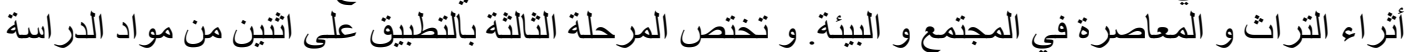

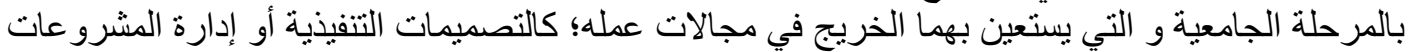

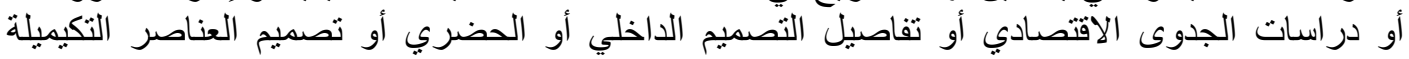

Journal of Engineering Sciences, Assiut University, Faculty of Engineering, Vol. 41, No. 6, November, 2013,E-mail address: jes@aun.edu.eg 
ولاء السيد يوسف، دراسة مشروع تخرج قسم العمارة كلية الفنون الجميلة جامعة الإسكندرية طبقاً للمعابير الأكاديمية،

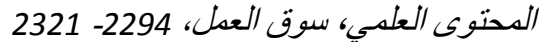

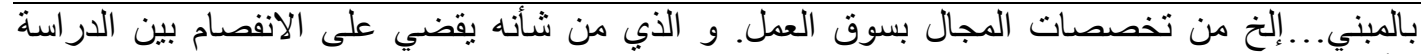

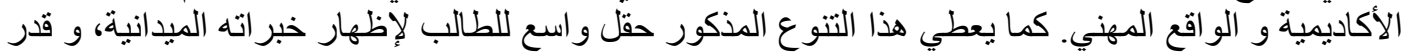

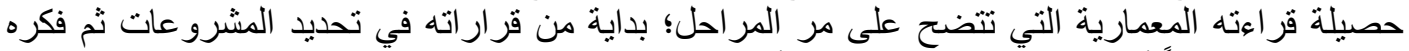

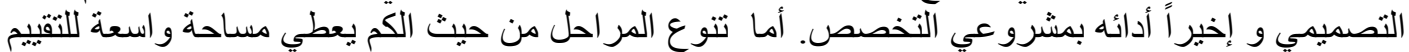

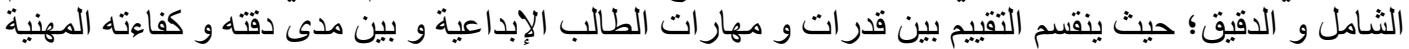

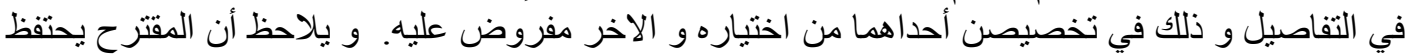
بنظام التقويم الذاتي و الإقليمي في نهاية المشروع.

خمسة عثر أسبوع (بواقع .rاعية أمبوعبا)

\begin{tabular}{|c|c|c|c|c|c|}
\hline$\frac{1}{4}+$ & \multicolumn{3}{|c|}{ से } & Sylar & Mhen \\
\hline 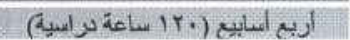 & \multicolumn{3}{|c|}{ 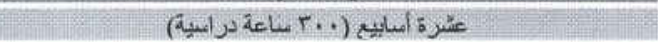 } & 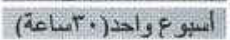 & (s) \\
\hline مجال التخصص & \multicolumn{3}{|c|}{ التصميم المعماري المتكامل } & تحليد المنشوعات & yصف \\
\hline 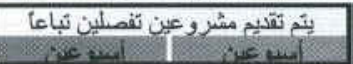 & \multicolumn{3}{|c|}{ 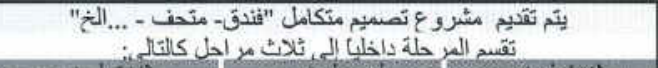 } & |حيد الطالب الآتى & \multirow[b]{2}{*}{ What } \\
\hline 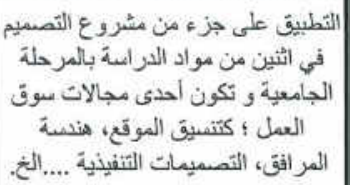 & ليثل تحليل التصنمينم طبقاً & التصميم المعماري & 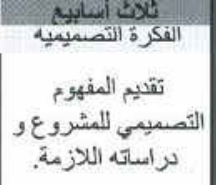 & 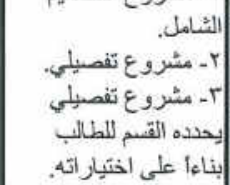 & \\
\hline قدرنه على اثتثان الثفاصيل في المجالات & \multirow{2}{*}{ 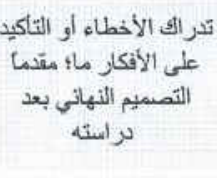 } & \multirow{2}{*}{ 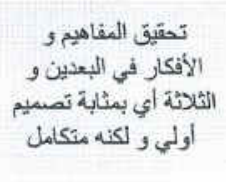 } & \multirow{2}{*}{ ورض المفهوم التصميه الفكري } & \multirow{2}{*}{ 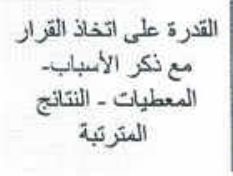 } & \multirow{2}{*}{$\frac{5}{5}$} \\
\hline اختيار الطالب عي مجلى الطالب فرض & & & & & \\
\hline تقتيبم كفاتئه المهينية في مجال & \multirow{2}{*}{\multicolumn{3}{|c|}{ مرحلة تقييبم مقترة الطالب الإبداعية و التصميمية }} & تقيبي توجه الططلب و & \multirow{2}{*}{ Aस्तi) } \\
\hline مفزوض عليه & & & & & \\
\hline
\end{tabular}

مخطط (3): مقتر ح الباحث لخطة تدريس مشروع تخرج قسم العمارة بكلية الفنون الجميلة جامعة الاسكندرية.

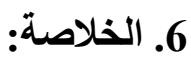

من الأخطاء الجسيمة التي تقع فيها مؤسسات التعليم المعماري أنها تسعى لتطبيق المعايير القياسية في حين

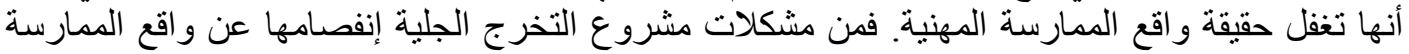

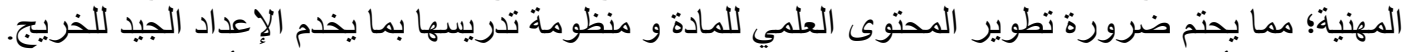

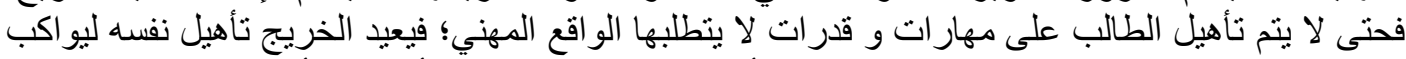

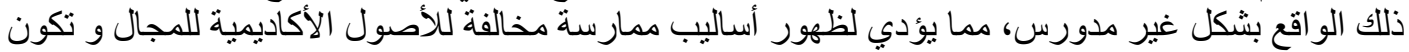

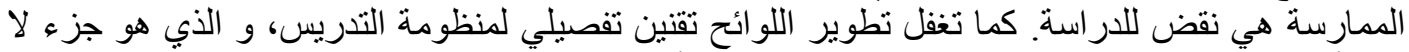

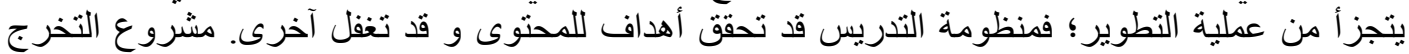

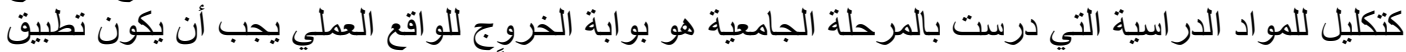

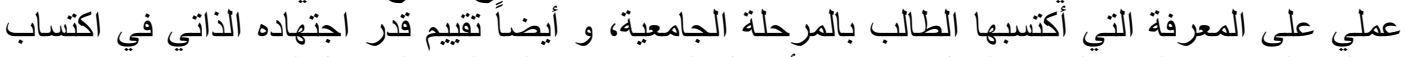

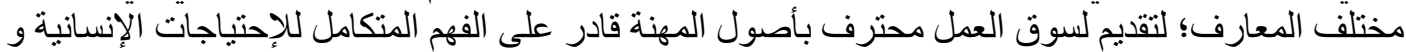

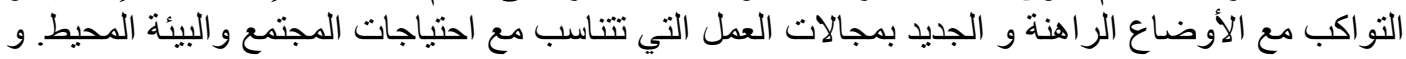
هذا الهذف المرجو من التعليم المعماري.

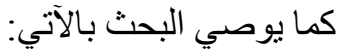

Journal of Engineering Sciences, Assiut University, Faculty of Engineering, Vol. 41, No. 6, November, 2013,E-mail address: jes@aun.edu.eg 
ولاء السبد بوسف، دراسة مشروع تخرج قسم العمارة كلية الفنون الجمبلة جامعة الإسكندرية طبقاً للمعابير الأكاديمية،

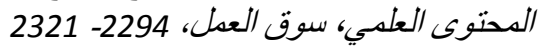
• أن تقوم عملية تطوير اللو ائح الدراسية على كل حزمة مو ادو على حدى طبقاً لما هو مطلوب منها و طبقاً

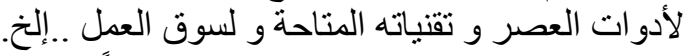

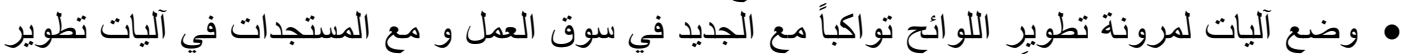

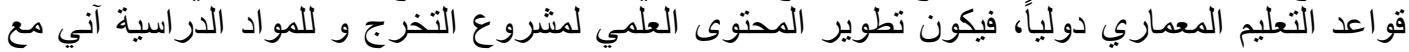

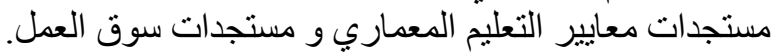

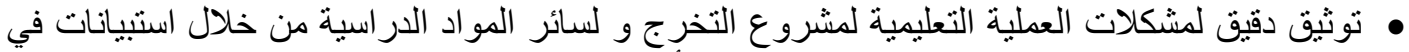

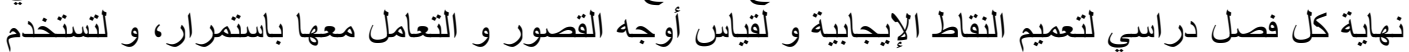

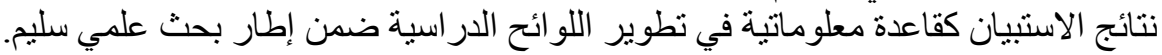

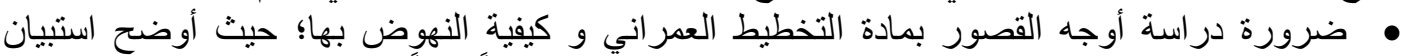
الطلاب و الخريجين أنها في ذيل قائمة تقدير اتهم، و هي مرتبطة أرتباطاً وثيقاً بمشروع التخرج.

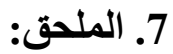

جدول (2)5: عدد الساعات الاسبو عية لقسم العمارة كلية الفنون الجميلة طبقاً للائحة الدر اسية 2006.

\begin{tabular}{|c|c|c|c|c|c|c|c|c|}
\hline \multicolumn{2}{|c|}{ التخصص (فنية) } & \multicolumn{2}{|c|}{ التخصص (هندسية) } & \multicolumn{2}{|r|}{ 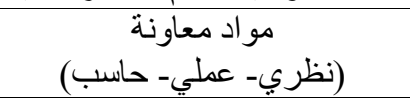 } & \multicolumn{2}{|r|}{ مو اد أساسية } & \multirow[t]{2}{*}{ ل لحزمة } \\
\hline 4 & نحت & 4 & رياضة & 6 & تتسيق موقع & 30 & تصميم شامل & \\
\hline 2 & تاريخ فن تشكيلى & 4 & هندسة وصفية & 4 & ظل و منظور & 40 & تصميم معماري & \multirow{12}{*}{$\begin{array}{l}\underline{\underline{E}} \\
\underline{\underline{E}} \\
\underline{\underline{\underline{L}}}\end{array}$} \\
\hline 4 & رسم & 8 & نظرية الإنشاءات & 8 & حاسب ثنائي و ثثلاثي الأبعاد & 12 & رسم معماري & \\
\hline 2 & أصول بحث علمى & 2 & |خو اص مقاومة المو اد & 8 & نظريات العمارة & 8 & تشكيل معماري & \\
\hline 9 & مو اد اختيارية & 2 & |إنشاءات معدنية & 6 & تاريخ العمارة & 42 & تصميمات تتفيذية & \\
\hline \multirow{2}{*}{4} & \multirow{2}{*}{ الفن والحضارة } & 2 & تربة وأساسات & 2 & در اسات بيئية & 16 & إنشاء معماري & \\
\hline & & 8 & خرسانة مسلحة & 2 & در اسات جدوى & \multirow{2}{*}{12} & تصميم حضري & \\
\hline \multirow{2}{*}{2} & \multirow{2}{*}{ تاريخ حضارة } & 4 & مســاحة & 2 & نظم و ادارة المو اقع & & و تخطيط مدن" & \\
\hline & & & & 2 & تثريعات عمر انية_ معمارية & & & \\
\hline \multirow[t]{4}{*}{2} & تذوق فني & & & 2 & المو اصفات العامة و الكميات & & & \\
\hline & & & & 3 & هندسة مر افق صحية & & & \\
\hline & & & & 3 & تجهيزات فنية & & & \\
\hline & & & & 3 & دراسات تمهيدية لمشروع & & & \\
\hline \multicolumn{2}{|r|}{ 29 ساعة } & \multirow{2}{*}{\multicolumn{2}{|c|}{$\begin{array}{l}\text { \% } 34 \\
\text { \%اعة } 11\end{array}$}} & & إعاعة 51 ساعة & \multirow{2}{*}{\multicolumn{2}{|c|}{$\begin{array}{l}156 \\
\text { ساعة } 51\end{array}$}} & الإجمالي \\
\hline & $\% 9$ & & & & $\% 19$ & & & النسبة \\
\hline
\end{tabular}

جدول(3)": حصر نوجهات الطلاب في اختبار مشرو عاتهم على مدى الثلاث أعواج الجامعية (2011 : 2013).

\begin{tabular}{|c|c|c|c|c|c|c|c|c|c|c|c|c|c|c|}
\hline \multicolumn{11}{|c|}{ نوعية المشرو عات } & \multirow{2}{*}{\begin{tabular}{|l} 
\\
\\
$\underline{E}$ \\
$\underline{E}$ \\
$\underline{E}$ \\
\end{tabular}} & \multirow{2}{*}{ E: } & \multirow{2}{*}{ 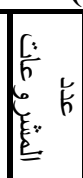 } & \multirow{2}{*}{$\begin{array}{l}q \\
\underline{E} \\
\underline{E} \\
E\end{array}$} \\
\hline الهنط: & أخرى & إسكاني & طليمي & علاجي & فندقي & رياض & |ترفيهي & تجاري & |إداري| & متحفي & & & & \\
\hline 2 & 5 & 18 & 14 & 24 & 20 & 8 & 13 & 19 & 12 & 19 & |العدد & \multirow{2}{*}{ |منطقة المكرك } & \multirow{2}{*}{154} & \multirow{2}{*}{$\begin{array}{c}-2010 \\
2011\end{array}$} \\
\hline$\% 1.3$ & $\% 3.2$ & $\% 11.1$ & $\% 9.1$ & $\% 15.6$ & $\% 13$ & $\% 5.2$ & $\% 8.5^{0}$ & $\overline{\% 12.3 .}$ & $\% 7.8$ & $\% 12.33$ & $\%$ & & & \\
\hline 3 & 4 & 10 & 11 & 28 & 27 & 4 & \begin{tabular}{|l|l}
18 \\
\end{tabular} & 20 & 15 & 18 & العدد & \multirow{2}{*}{ ساحل بحيرة } & \multirow{2}{*}{158} & \multirow{2}{*}{$\begin{array}{l}-2011 \\
2012\end{array}$} \\
\hline$\% 1.9$ & $\% 2.5$ & $\% 11.4$ & $\% 7$ & $\% 18.2$ & $\% 17.5$ & $\% 2.5$ & $\% 11.4 \mid$ & $\% 12$ & $\% 9.5$ & \%11.4 & $\%$ & & & \\
\hline
\end{tabular}

Journal of Engineering Sciences, Assiut University, Faculty of Engineering, Vol. 41, No. 6, November, 2013,E-mail address: jes@aun.edu.eg 
2314

ولاء السيب يوسف، دراسة مشروع تخرج قسم العمارة كلية الفنون الجمبلة جامعة الإسكندرية طبقاً للمعابير الأكاديية،

\begin{tabular}{|c|c|c|c|c|c|c|c|c|c|c|c|c|c|c|}
\hline & & & & & & & & & & & & الجنوبي & & \\
\hline 4 & 5 & 15 & 13 & 26 & 24 & 7 & 12 & 20 & 14 & 19 & |العدد & \multirow{2}{*}{ كفر عشر البصل و } & \multirow{2}{*}{159} & \multirow{2}{*}{$\begin{array}{c}-2012 \\
2013\end{array}$} \\
\hline$\% 2.5$ & $\% 3.1$ & $\% 9.4$ & $\% 8.2$ & 016. & $\% 15.1$ & $\% 4.4$ & $\% 7.5$ & $\% 12.6$ & $\% 8.8$ & $\% 12$ & $\partial^{0}$ & & & \\
\hline
\end{tabular}

جدول (4): اسنبيان منوسط مستوى طلاب مشروع التخرج.

\begin{tabular}{|c|c|c|c|c|c|c|c|c|c|}
\hline- & مقبول & جيذ & & جيد جدا & إمتياز & & & & س1: \\
\hline- & 8 & 18 & & 6 & - & \multirow{2}{*}{\multicolumn{2}{|c|}{ النسبة }} & \multirow{2}{*}{\multicolumn{2}{|c|}{ |السنوات الدراسية السابقة في الأربع }} \\
\hline- & $\% 25$ & $\% 56.2$ & & $\% 18.75$ & - & & & & \\
\hline (فنية) مواد) & (هندسية) & تخصص معادة & & | تخطيط عمر الحضريم & لتنفيذية & & الثعامل ألميم & & \\
\hline 2 & 9 & 13 & & 0 & 3 & & 5 & بي العدد & أعلى تقدير لديك في \\
\hline$\% 6.25$ & $\% 28.13$ & $\% 40.63$ & & - & $\% 9.3$ & & $\% 15.63$ & | النسبة & المراني" \\
\hline
\end{tabular}

\begin{tabular}{|c|c|c|c|c|c|}
\hline أكثر & ستة أشهر & خمسة أشهر & أربعة أشهر & ثلاثة أشهر & 1-3س \\
\hline 1 & 4 & - & 6 & 21 & عدد أشهر تدرييك الصيفي|العدد \\
\hline$\% 3.13$ & $\% 12.5$ & - & $\% 18.75$ & $\% 65.67$ & السابقة مدى السنو ات الدر اسياه| (لنسبة \\
\hline عحاضر ات عامة & \multicolumn{2}{|c|}{ ورش عمل } & 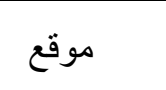 & مكتب & 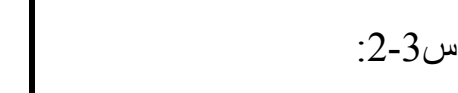 \\
\hline 21 & \multicolumn{2}{|c|}{5} & 3 & 3 & \multirow{2}{*}{ نوع تدرييك الصيفي } \\
\hline$\% 65.67$ & \multicolumn{2}{|c|}{15.63} & $\% 9.38$ & $\% 9.38$ & \\
\hline
\end{tabular}

\begin{tabular}{|c|c|c|c|c|c|c|c|c|c|c|c|c|c|c|}
\hline \multicolumn{4}{|c|}{ المو اد المعاونة } & \multicolumn{5}{|c|}{ التصميمات التنفيذية } & \multicolumn{5}{|c|}{ تصميم معماري- حضري- } & \multirow[t]{2}{*}{$:^{* * 3} 3-3 w$} \\
\hline$ه$ & 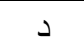 & ج & با با & هـ & د & ج & ب & أ & هـ & د & ج & ب ب & أ & \\
\hline 28 & 3 & 1 & - & 18 & 10 & - & - & 4 & - & 18 & 7 & 6 & 1 & تطبيقلك \\
\hline $\begin{array}{l}87 . \\
\% 5\end{array}$ & $\begin{array}{c}9.38 \\
\%\end{array}$ & $\begin{array}{c}3.13 \\
\%\end{array}$ & 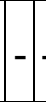 & $\begin{array}{c}56.2 \\
\% 5\end{array}$ & $\begin{array}{c}31.4 \\
\%\end{array}$ & - & - & $\begin{array}{c}12.5 \\
\%\end{array}$ & - & $\begin{array}{l}56.2 \\
\% 5\end{array}$ & $\begin{array}{l}21.8 \\
\% 8\end{array}$ & $\begin{array}{l}18.7 \\
\% 5\end{array}$ & $\begin{array}{c}3.13 \\
\%\end{array}$ & باللدريب الصبة الأكاديمية \\
\hline 28 & 2 & 2 & - & 18 & 10 & - & - & 4 & - & 17 & 5 & 7 & 3 & مدى استفادتك من \\
\hline $\begin{array}{l}87 . \\
\% 5\end{array}$ & $\begin{array}{c}6.25 \\
\%\end{array}$ & $\begin{array}{c}6.25 \\
\%\end{array}$ & & $\begin{array}{l}56.2 \\
\% 5\end{array}$ & $\begin{array}{c}31.4 \\
\%\end{array}$ & - & - & $\begin{array}{c}12.5 \\
\%\end{array}$ & - & $\begin{array}{l}53.1 \\
\% 3\end{array}$ & $\begin{array}{c}15.6 \\
3\end{array}$ & $\begin{array}{c}21.8 \\
\% 8\end{array}$ & $\begin{array}{c}9.38 \\
\%\end{array}$ & صيفي \\
\hline
\end{tabular}

* في ورقة استيبان الطلاب: السؤال الثالث مرتبط بنوع التندريب المذكور في السؤ ال الرابع.

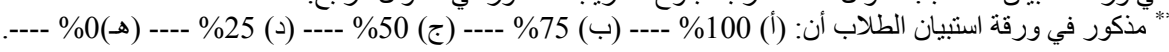

Journal of Engineering Sciences, Assiut University, Faculty of Engineering, Vol. 41, No. 6, November, 2013,E-mail address: jes@aun.edu.eg 
ولاء السيد يوسف، دراسة مشروع تخرج قسم العمارة كلية الفنون الجميلة جامعة الإسكندرية طبقاً للمعابير الأكاديمية، المحتوى العلمي، سوق العهل، 2294- 2321

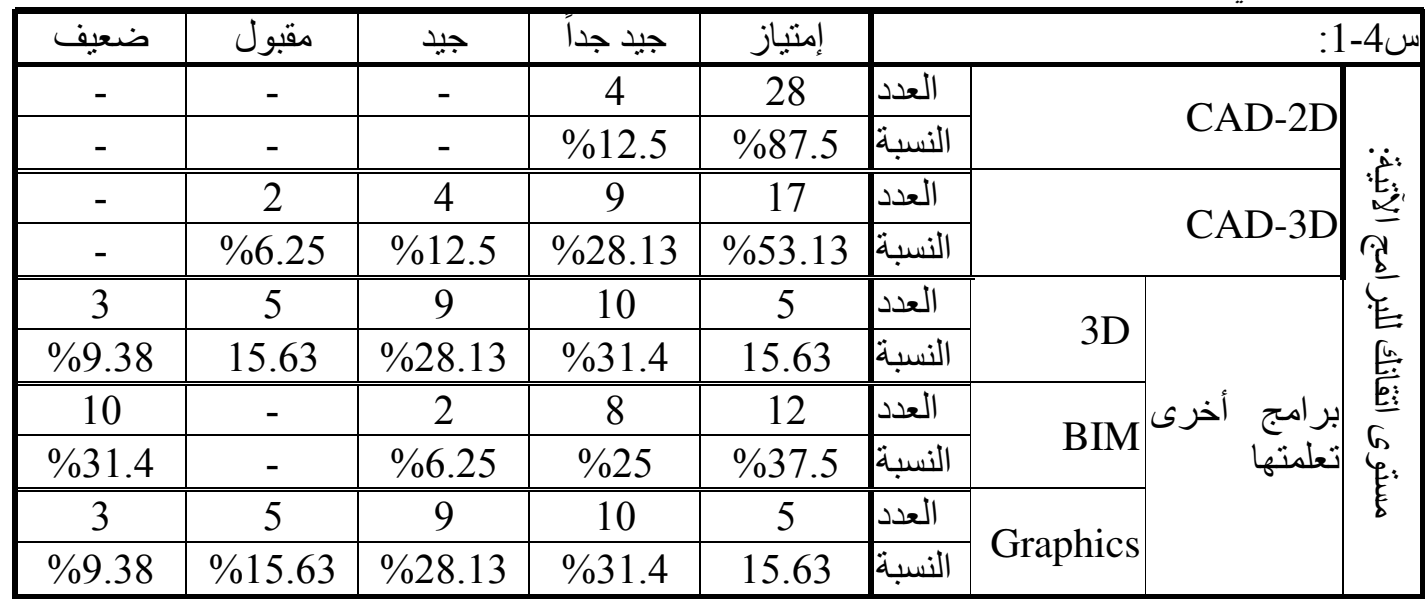

\begin{tabular}{|c|c|c|c|c|c|c|c|c|c|c|c|c|c|c|c|c|}
\hline \multicolumn{5}{|c|}{ التدريب الصيفي. } & \multicolumn{5}{|c|}{ التصميمات التنفيذية } & \multicolumn{5}{|c|}{ تصميم معماري- حضري- تخطيط } & \multirow{2}{*}{\multicolumn{2}{|c|}{ س4-2-2 }} \\
\hline هـ & 2 & ج & ب & I & $\rightarrow$ & د & ج & با & i & $ه$ & \begin{tabular}{|l|} 
\\
\end{tabular} & ج & ب & I & & \\
\hline 21 & 5 & 3 & - & 3 & - & - & - & - & 32 & - & - & 5 & 14 & 13 & & $\dot{q}$ \\
\hline $\begin{array}{c}65.67 \\
\% \\
\end{array}$ & $\begin{array}{c}15.63 \\
\%\end{array}$ & $\% 9.38$ & - & $\begin{array}{c}9.38 \\
\%\end{array}$ & - & - & - & & $\begin{array}{c}100 \\
\%\end{array}$ & - & - & $\begin{array}{c}15.63 \\
\%\end{array}$ & $\begin{array}{c}43.75 \\
\%\end{array}$ & $\begin{array}{c}40.63 \\
\%\end{array}$ & $2 \mathrm{D}$ & ". \\
\hline 21 & 8 & 2 & - & 2 & 28 & 4 & - & - & - & - & - & 6 & 14 & 12 & & \\
\hline $\begin{array}{c}65.67 \\
\% \\
\end{array}$ & $\% 25$ & $\% 6.26$ & - & $\begin{array}{c}6.25 \\
\% \\
\end{array}$ & $\% 87.5$ & $\% 12.5$ & -1 & - & - & - & - & $\begin{array}{c}18.75 \\
\%\end{array}$ & $\begin{array}{c}43.75 \\
\%\end{array}$ & $\% 37.5$ & $3 \mathrm{D}$ & $\underline{\varepsilon}$ \\
\hline 21 & 4 & 4 & 3 & - & 28 & 4 & - & - & - & 5 & 3 & 1 & 3 & 20 & & \\
\hline $\begin{array}{c}65.67 \\
\%\end{array}$ & $\% 12.5$ & $\% 12.5$ & $\begin{array}{c}9.3 \\
8 \\
\%\end{array}$ & - & $\% 87.5$ & $\% 12.5$ & - & - & - & 15.63 & $\% 9.38$ & $\% 3.13$ & $\% 9.38$ & $\% 62.5$ & 3D & $\begin{array}{l}f \\
b \\
5 \\
5 \\
5\end{array}$ \\
\hline 21 & 7 & 3 & - & 1 & 18 & 14 & - & - & - & 6 & 1 & 1 & 10 & 14 & & \\
\hline $\begin{array}{c}65.67 \\
\% \\
\end{array}$ & $\begin{array}{c}21.88 \\
\%\end{array}$ & $\% 9.38$ & - & $\begin{array}{c}3.13 \\
\%\end{array}$ & $\begin{array}{c}56.25 \\
\% \\
\end{array}$ & $\begin{array}{c}43.75 \\
\% \\
\end{array}$ & - & - & - & $\begin{array}{c}18.75 \\
\% \\
\end{array}$ & $\% 3.13$ & $\% 3.13$ & $\% 31.4$ & $\begin{array}{c}43.75 \\
\%\end{array}$ & BIM & \\
\hline 21 & 4 & 4 & 3 & - & 31 & 1 & - & - & - & 5 & 3 & 1 & 3 & 20 & & \\
\hline $\begin{array}{c}65.67 \\
\%\end{array}$ & $\% 12.5$ & $\% 12.5$ & $\begin{array}{c}9.3 \\
8 \\
\%\end{array}$ & - & $\begin{array}{c}96.88 \\
\%\end{array}$ & $\% 3.13$ & & - & - & 15.63 & $\% 9.38$ & $\% 3.13$ & $\% 9.38$ & $\% 62.5$ & $\begin{array}{c}\text { Graphi } \\
\text { cs }\end{array}$ & \\
\hline
\end{tabular}

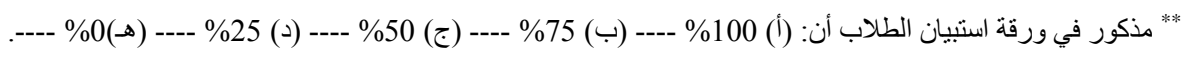
Journal of Engineering Sciences, Assiut University, Faculty of Engineering, Vol. 41, No. 6, November, 2013,E-mail address: jes@aun.edu.eg 
ولاء السبي بوسف، دراسة مشروع تخرج قسم العمارة كلبة الفنون الجميلة جامعة الإسكندرية طبقاً للمعابير الأكاديبية،

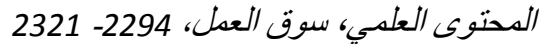
جدول (5) 12:استبيان مدى تطبيق طلاب مشروع سوع التخر ج لدر استهم الأكاديمية في مشروع التخرج.

\begin{tabular}{|c|c|c|c|c|c|c|c|c|}
\hline \multicolumn{2}{|c|}{ مرحلة الو اجهات و الكنل } & \multicolumn{2}{|c|}{ مرحلة المساقط الأفقية } & \multicolumn{2}{|c|}{ مرحلة الفكرة التصميمة } & \multirow{2}{*}{\multicolumn{3}{|c|}{ لمشروع استعانتك بالآتي في مر احل التخرجة }} \\
\hline لا استعين به & استعين به & لا استعين به & |ستعين به & لا استعين به & استعين بها & & & \\
\hline - & 32 & - & 32 & - & 32 & العدد & \multirow{2}{*}{\multicolumn{2}{|c|}{ |و شامل }} \\
\hline- & $\% 100$ & - & $\% 100$ & - & $\% 100$ & النسبة & & \\
\hline 30 & 2 & 32 & - & 32 & - & العدد & \multirow{2}{*}{\multicolumn{2}{|c|}{ تصفيذيمات }} \\
\hline$\% 93.75$ & $\% 6.25$ & $\% 100$ & - & $\% 100$ & - & النسبة & & \\
\hline 27 & 5 & 21 & 11 & 20 & 12 & العدد & \multirow{2}{*}{\multicolumn{2}{|c|}{ |تضطيط حضرن و و }} \\
\hline 84.27 & 15.63 & $\% 65.67$ & $\% 34.33$ & $\% 63.5$ & $\% 37.5$ & النسبة & & \\
\hline 24 & 8 & 30 & 2 & 29 & 3 & العدد & \multirow{2}{*}{\multicolumn{2}{|c|}{ تشكيل معماري }} \\
\hline$\% 75$ & $\% 25$ & $\% 93.75$ & $\% 6.25$ & $\% 90.62$ & $\% 9.38$ & النسبة & & \\
\hline 29 & 3 & 27 & 5 & 30 & 2 & العدد & \multirow{2}{*}{\multicolumn{2}{|c|}{ تاريخ العمارة }} \\
\hline$\% 90.63$ & $\% 9.37$ & 84.27 & 15.63 & 93.75 & $\% 6.25$ & النسبة & & \\
\hline 28 & 4 & 21 & 11 & 27 & 5 & العدد & \multirow{2}{*}{\multicolumn{2}{|c|}{ |نظريات العمارة }} \\
\hline$\% 87.5$ & $\% 12.5$ & $\% 65.67$ & $\% 34.33$ & 84.27 & 15.63 & النسبة & & \\
\hline 32 & - & 32 & - & 32 & - & العدد & \multirow{2}{*}{\multicolumn{2}{|c|}{ ظل و منظور }} \\
\hline$\% 100$ & - & $\% 100$ & - & $\% 100$ & - & النسبة & & \\
\hline 25 & 7 & 30 & 2 & 27 & 5 & العدد & \multirow{2}{*}{\multicolumn{2}{|c|}{ ك }} \\
\hline$\% 78.12$ & $\% 21.88$ & 93.75 & $\% 6.25$ & 84.27 & 15.63 & النسبة & & \\
\hline 32 & - & 32 & - & 30 & 2 & العدد & \multirow{2}{*}{ در اسات جدوى } & \\
\hline$\% 100$ & - & $\% 100$ & - & $\% 93.75$ & $\% 6.25$ & النسبة & & \\
\hline 19 & 13 & 14 & 18 & - & 32 & العدد & \multirow{2}{*}{ در اسـات بيئية } & \\
\hline$\% 59.37$ & $\% 40.63$ & $\% 43.75$ & $\% 56.25$ & - & $\% 100$ & النسبة| & & \\
\hline 21 & 11 & 20 & 12 & 30 & 2 & العدد & \multirow{2}{*}{\multicolumn{2}{|c|}{ تتسيق موقع }} \\
\hline$\% 65.67$ & $\% 34.33$ & $\% 63.5$ & $\% 37.5$ & 93.75 & $\% 6.25$ & النسبة & & \\
\hline 32 & - & 32 & - & 32 & - & العدد & \multirow{2}{*}{\multicolumn{2}{|c|}{ |نظم اقع }} \\
\hline$\% 100$ & - & $\% 100$ & - & $\% 100$ & - & النسبة & & \\
\hline 32 & - & 32 & - & 32 & - & العدد & \multirow{2}{*}{\multicolumn{2}{|c|}{ |هندسة }} \\
\hline$\% 100$ & - & $\% 100$ & - & $\% 100$ & - & النسبة & & \\
\hline 32 & - & 32 & - & 32 & - & العدد & \multirow{2}{*}{\multicolumn{2}{|c|}{ |المو اصفات }} \\
\hline$\% 100$ & - & $\% 100$ & - & $\% 100$ & - & النسبة & & \\
\hline 32 & - & 32 & - & 32 & - & العدد & \multirow{2}{*}{\multicolumn{2}{|c|}{ تجهيز ات فنية }} \\
\hline$\% 100$ & - & $\% 100$ & - & $\% 100$ & - & النسبة & & \\
\hline 26 & 6 & 19 & 13 & 7 & 25 & العدد & \multirow{2}{*}{ CAD-2D } & E \\
\hline$\% 71.25$ & $\% 18.75$ & $\% 59.37$ & $\% 40.63$ & $\% 21.88$ & $\% 78.12$ & النسبة & & \\
\hline
\end{tabular}

Journal of Engineering Sciences, Assiut University, Faculty of Engineering, Vol. 41, No. 6, November, 2013,E-mail address: jes@aun.edu.eg 
ولاء السيد بوسف، دراسة مشروع تخرج قسم العدارة كلية الفنون الجمبلة جامعة الإسكندرية طبقاً للمعابير الأكاديبية، المحتوى العلمي، سوق العمل، 2294- 2321

\begin{tabular}{|c|c|c|c|c|c|c|c|c|}
\hline \multicolumn{2}{|c|}{ مرحلة الو اجهات و الكتل } & \multicolumn{2}{|c|}{ مرحلة المساقط الأفقية } & \multicolumn{2}{|c|}{ مرحلة الفكرة التصميمة } & \multirow{2}{*}{\multicolumn{3}{|c|}{ لمشروع التخرانتك بالآتي في مر احلفة: }} \\
\hline لا استعين به & استعين بـه & لا استعين به & |ستعين به | & لا استعين به & استعين بـه & & & \\
\hline 7 & 25 & 25 & 7 & 28 & 4 & العدد & CAD-3D & \\
\hline$\% 21.88$ & $\% 78.12$ & $\% 78.12$ & $\% 21.88$ & $\% 87.5$ & $\% 12.5$ & النسبة & $3 \mathrm{D}$ & \\
\hline 10 & 22 & 10 & 22 & 30 & 2 & العدد & & \\
\hline$\% 31.4$ & $\% 68.6$ & $\% 31.4$ & $\% 68.6$ & 93.75 & $\% 6.25$ & النسبة & DI & \\
\hline 20 & 12 & 25 & 7 & - & 32 & 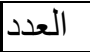 & & \\
\hline$\% 63.5$ & $\% 37.5$ & $\% 78.12$ & $\% 21.88$ & - & $\% 100$ & النسبة & Graphics & \\
\hline 28 & 4 & 28 & 4 & 28 & 4 & العدد ال العد & & \\
\hline$\% 87.5$ & $\% 12.5$ & $\% 87.5$ & $\% 12.5$ & $\% 87.5$ & $\% 12.5$ & النسبة & & \\
\hline 27 & 5 & 28 & 4 & 29 & 3 & العدد | - العد & & $\underline{E}$ \\
\hline 84.27 & 15.63 & $\% 87.5$ & $\% 12.5$ & $\% 90.62$ & $\% 9.38$ & النسبة & & \\
\hline 24 & 8 & 24 & 8 & 24 & 8 & العدد & & \\
\hline$\% 75$ & $\% 25$ & $\% 75$ & $\% 25$ & $\% 75$ & $\% 25$ & النسبة & & \\
\hline 29 & 3 & 29 & 3 & 29 & 3 & العدد & مقالات تحليلية و & \\
\hline$\% 90.62$ & $\% 9.38$ & $\% 90.62$ & $\% 9.38$ & $\% 90.62$ & $\% 9.38$ & النسبة & & \\
\hline- & 32 & - & 32 & - & 32 & العدد & منظورية & そ̌ \\
\hline- & $\% 100$ & - & $\% 100$ & - & $\% 100$ & النسبة & لمشرو عات & $\underline{2}$ \\
\hline 24 & 8 & 15 & 17 & 19 & 13 & العدد & |رسومات هندسية & \\
\hline$\% 75$ & $\% 25$ & $\% 46.87$ & $\% 53.13$ & $\% 59.37$ & $\% 40.63$ & النسبة & لمشرو عات & \\
\hline
\end{tabular}

\begin{tabular}{|c|c|c|c|c|c|c|c|c|c|c|c|}
\hline \multicolumn{12}{|c|}{ جدول (6)12:استبيان مستوى خريجي القسم و مجالات عملهم. } \\
\hline 2012 & 2011 & 2010 & 2009 & 2008 & 2007 & 2006 & 2005 & 2004 & 2003 & & \\
\hline 3 & 5 & 6 & 3 & 2 & 4 & 5 & 5 & 3 & 4 & عدد & سنة \\
\hline$\% 7.5$ & $\% 12.5$ & $\% 15$ & $\% 7.5$ & $\% 5$ & $\% 10$ & 12.5 & $\% 12.5$ & $\% 7.5$ & $\% 10$ & نسبة & 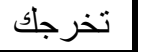 \\
\hline
\end{tabular}

\begin{tabular}{|c|c|c|c|c|c|c|}
\hline- & مقبول & جيد & جيد جداً & إمتياز & & س2: \\
\hline- & 12 & 24 & 4 & - & عدد & \multirow{2}{*}{ تقديرك العام } \\
\hline & $\% 15$ & $\% 75$ & $\% 10$ & - & نسبة & \\
\hline- & 3 & 20 & 14 & 3 & عدد & \multirow{2}{*}{ تقدير مشروع تخرجك } \\
\hline- & $\% 7.5$ & $\% 50$ & $\% 35$ & $\% 7.5$ & نسبة & \\
\hline
\end{tabular}

\begin{tabular}{|c|c|c|c|c|c|c|c|}
\hline أخد مواد ألحص & أحد مو اد & أحد المواد & تخطيط عمر الحضري و التصميم & التصفيمات & 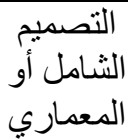 & & س3: \\
\hline 2 & 12 & 16 & 0 & 4 & 6 & عدد & \multirow{2}{*}{ أثناء در اساتلك الجادير لمادة در اسية } \\
\hline$\% 5$ & $\% 30$ & $\% 40$ & ----- & $\% 10$ & $\% 15$ & نسبة & \\
\hline
\end{tabular}

Journal of Engineering Sciences, Assiut University, Faculty of Engineering, Vol. 41, No. 6, November, 2013,E-mail address: jes@aun.edu.eg 
2318

ولاء السيب يوسف، دراسة مشروع تخرج قسم العمارة كلية الفنون الجمبلة جامعة الإسكندرية طبقاً للمعابير الأكاديمبة،

\begin{tabular}{|c|c|c|c|c|c|c|c|c|}
\hline- & مقبول & جيد & جيد جداً & إمتياز & & & & س4: \\
\hline- & - & - & 3 & 37 & عدد & \multirow{2}{*}{\multicolumn{2}{|c|}{ CAD-2D }} & \\
\hline- & - & - & $\% 7.5$ & $\% 92.5$ & نسبة & & & \\
\hline- & - & 6 & 15 & 19 & عدد & \multirow{2}{*}{\multicolumn{2}{|c|}{ CAD-3D }} & \\
\hline- & - & $\% 15$ & $\% 37.5$ & $\% 47.5$ & نسبة & & & \\
\hline 7 & 5 & 9 & 13 & 6 & عدد & \multirow{2}{*}{$3 \mathrm{D}$} & \multirow{6}{*}{ | بر امرى } & 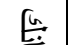 \\
\hline$\% 17.5$ & $\% 12.5$ & $\% 22.5$ & $\% 32.5$ & $\% 15$ & نسبة & & & \\
\hline 7 & 10 & 9 & 4 & - & عدد & \multirow{2}{*}{ BIM } & & $\xi$ \\
\hline$\% 17.5$ & $\% 25$ & $\% 22.5$ & $\% 10$ & - & نسبة & & & \\
\hline 7 & 4 & 9 & 13 & 6 & عدد & \multirow{2}{*}{$\begin{array}{r}\text { Graphic } \\
\mathrm{s}\end{array}$} & & \\
\hline$\% 17.5$ & $\% 10$ & $\% 22.5$ & $\% 32.5$ & $\% 15$ & نسبة & & & \\
\hline
\end{tabular}

\begin{tabular}{|c|c|c|c|c|c|c|c|c|c|c|c|}
\hline اخرى & إسكاني & تعليمي & علاجي & فندقي & ياضي & ترفيهي & تجاري & إداري & متحفي & & س 5: \\
\hline 2 & 4 & 3 & 6 & 6 & 2 & 4 & 5 & 3 & 5 & عدد & \\
\hline$\% 5$ & $\% 10$ & $\% 7.5$ & $\% 15$ & $\% 15$ & $\% 5$ & $\% 10$ & $\begin{array}{c}12.5 \\
\%\end{array}$ & $\begin{array}{l}7.5 \\
\%\end{array}$ & $\begin{array}{c}12.5 \\
\%\end{array}$ & نسبة & "ُروع التخرج| \\
\hline
\end{tabular}

جدول (7)12: استبيان علاقة الدر اسة الأكاديمية و مشروع التخرج بالمسار المهني لخريجي القسم.

\begin{tabular}{|c|c|c|c|c|c|c|c|c|c|}
\hline الصيالة & الصر افقة & النماذج & المشرورعات & على الإشتر افذ & الرستوماتية & التصميم & & & س1: \\
\hline 3 & 2 & 1 & 2 & 9 & 11 & 2 & عدد & \multirow{2}{*}{ المعماريم } & \multirow[b]{2}{*}{ sis } \\
\hline$\% 7.5$ & $\% 5$ & $\% 2.5$ & $\% 5$ & $\% 22.5$ & $\% 27.5$ & $\% 5$ & نسبة & & \\
\hline- & - & - & - & 1 & 1 & - & عدد & \multirow{2}{*}{ تخطيط المدن } & \\
\hline- & - & - & - & $\% 2.5$ & $\% 2.5$ & - & نسبة & & \\
\hline 1 & - & - & - & - & 3 & - & عدد & \multirow{2}{*}{ الحضريم } & $\underline{E}$ \\
\hline$\% 2.5$ & - & - & - & - & $\% 7.5$ & - & نسبة & & $6:$ \\
\hline- & - & 1 & - & \multicolumn{2}{|c|}{2} & - & عدد & \multirow{2}{*}{ تنسيق حدائق } & \\
\hline- & - & $\% 2.5$ & - & & 5 & - & نسبة & & $\Leftrightarrow$ \\
\hline- & - & - & - & \multicolumn{3}{|c|}{1} & عدد & \multirow{2}{*}{ التصميم } & $\bar{\xi}$ \\
\hline- & - & - & - & \multicolumn{3}{|c|}{$\% 2.5$} & نسبة & & \\
\hline
\end{tabular}

\begin{tabular}{|c|c|c|c|c|c|c|}
\hline \multicolumn{5}{|c|}{ مدى أستعانتك بتلك المو اد الدر اسية في مسارك المهني } & & \multirow{2}{*}{ : } \\
\hline هـ & د & ج & ب & أ & & \\
\hline 27 & - & 8 & 3 & 2 & عدد & \multirow{2}{*}{ تصميم معماري } \\
\hline$\% 67.5$ & - & $\% 20$ & $\% 7.5$ & $\% 5$ & نسبة & \\
\hline 26 & - & 7 & 4 & 3 & 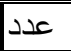 & تصميم شامل \\
\hline
\end{tabular}

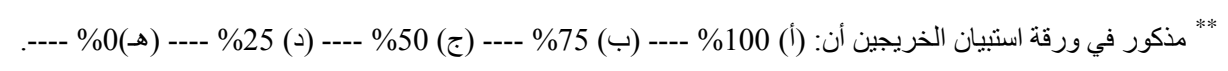

Journal of Engineering Sciences, Assiut University, Faculty of Engineering, Vol. 41, No. 6, November, 2013,E-mail address: jes@aun.edu.eg 
ولاء السبي بيوسف، دراسة مشروع تخرج قسم العدارة كلبة الفنون الجمبلة جامعة الإسكندرية طبقاً للمعابيير الأكادبية، المحتوى العلمي، سوق العمل، 2294- 2321

\begin{tabular}{|c|c|c|c|c|c|c|}
\hline$\% 65$ & - & $\% 17.5$ & $\% 10$ & $\% 7.5$ & نسبة & \\
\hline 2 & 2 & 2 & 6 & 28 & عدد & \multirow{2}{*}{ تصميمات تنفيذية } \\
\hline$\% 5$ & $\% 5$ & $\% 5$ & $\% 15$ & $\% 35$ & نسبة & \\
\hline 25 & 10 & 5 & - & - & عدد & \multirow{2}{*}{ تخطيط مدن و تصميم حضري } \\
\hline$\% 62.5$ & $\% 25$ & $\% 12.5$ & - & - & نسبة & \\
\hline 25 & 4 & 6 & 2 & 3 & عدد & \multirow{2}{*}{ تشكيل معماري } \\
\hline$\% 62.5$ & $\% 10$ & $\% 15$ & $\% 5$ & $\% 7.5$ & نسبة & \\
\hline 36 & 2 & - & 1 & 1 & عدد & \multirow{2}{*}{ ت اريخ العمارة } \\
\hline$\% 90$ & $\% 5$ & - & $\% 2.5$ & $\% 2.5$ & نسبة & \\
\hline 31 & 3 & 1 & 2 & 3 & عدد & \multirow{2}{*}{ نظريات العمارة } \\
\hline$\% 77.5$ & $\% 7.5$ & $\% 2.5$ & $\% 5$ & $\% 7.5$ & نسبة & \\
\hline 29 & 4 & 4 & 2 & 1 & عدد & \multirow{2}{*}{ ظل و منظور } \\
\hline$\% 72.5$ & $\% 10$ & $\% 10$ & $\% 5$ & $\% 2.5$ & نسبة & \\
\hline- & 5 & 10 & 10 & 15 & عدد & \multirow{2}{*}{ تشريعات عمر انية و معمارية } \\
\hline- & $\% 12.5$ & $\% 25$ & $\% 25$ & $\% 37.5$ & نسبة & \\
\hline- & 10 & 12 & 14 & 4 & عدد & \multirow{2}{*}{ در اسات جدوى اقتصادية } \\
\hline- & $\% 25$ & $\% 30$ & $\% 35$ & $\% 10$ & نسبة & \\
\hline 29 & 2 & 8 & - & 1 & عدد & \multirow{2}{*}{ در اسات بيئية } \\
\hline$\% 72.5$ & $\% 5$ & $\% 20$ & - & $\% 2.5$ & نسبة & \\
\hline 20 & 5 & 6 & 5 & 4 & عدد & \multirow{2}{*}{ تنسيق موقع } \\
\hline$\% 50$ & $\% 12.5$ & $\% 15$ & $\% 12.5$ & $\% 10$ & نسبة & \\
\hline- & & 3 & 8 & 29 & عدد & \multirow{2}{*}{ نظم و ادارة المو اقع } \\
\hline- & & $\% 7.5$ & $\% 20$ & $\% 72.5$ & نسبة & \\
\hline- & - & 3 & 12 & 25 & عدد & \multirow{2}{*}{ هندسة مر افق صحية } \\
\hline- & - & $\% 7.5$ & $\% 12.5$ & $\% 62.5$ & نسبة & \\
\hline- & 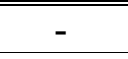 & 4 & 4 & 32 & عدد & \multirow{2}{*}{ المو اصفات العامة و الكميات } \\
\hline- & - & $\% 10$ & $\% 10$ & $\% 80$ & نسبة & \\
\hline- & - & 1 & 3 & 36 & عدد & \multirow{2}{*}{ تجهيز ات فنية } \\
\hline- & - & $\% 2.5$ & $\% 7.5$ & $\% 90$ & نسبة & \\
\hline 31 & - & 2 & 4 & 3 & عدد & \multirow{2}{*}{ 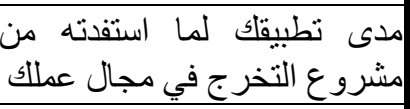 } \\
\hline$\% 77.5$ & - & $\% 5$ & $\% 10$ & $\% 7.5$ & نسبة| & \\
\hline 34 & - & 1 & 3 & 2 & عدد & \multirow{2}{*}{ بمجال عملكة موضوع مشروع التخرج } \\
\hline$\% 85$ & - & $\% 2.5$ & $\% 7.5$ & $\% 5$ & نسبة & \\
\hline
\end{tabular}

\begin{tabular}{|c|c|c|c|c|c|c|}
\hline أعمل على المشروع & أعمل في مقياس & ثلاث مشرو أو أكثر & 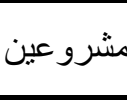 & مشروع & & \\
\hline 18 & 22 & - & 1 & 1 & عدد & د المشرو عات التي عملت بها \\
\hline$\% 45$ & $\% 55$ & - & $\% 2.5$ & $\% 2.5$ & نسبة & \\
\hline
\end{tabular}

Journal of Engineering Sciences, Assiut University, Faculty of Engineering, Vol. 41, No. 6, November, 2013,E-mail address: jes@aun.edu.eg 
1 David Nicole, Simon Pilling: Changing Architectural Education: Towards a New, Professionalism, Taylor\&Francis; 1 edition 2000, p 23.

2 Ashraf M. Salama: Beyond the Consumption of Knowledge: Questioning of and Questing for Future Forms of Pedagogy in Architectural Education, the Future of Architectural Education, Universiti Putra Malaysia, 2012.

3 هشام أبو سعدة: تعليم التصميم المعماري على ضوء العلاقة بين عملتي الإبداع و التصميم، مجلة الإمارات للبحوث الهندسية، 2003.

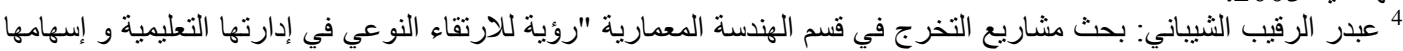

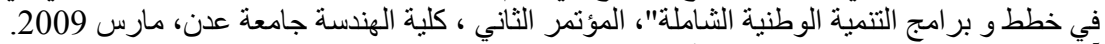

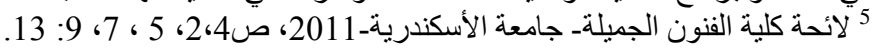

6 "UIA and Architectural Education Reflections and Recommendations", Document prepared by the UIA Architectural Education Commission, up-dated 05.11.2008.

- UIA Built Environment Education Guidelines, Paris, France, April 2002.

- Berlin 2002 XXI Congress \& XXII Assembly of the UIA - UIA Newsletter - April-May 2000.

- CAA, Qualifications in Architecture Recommended for Recognition by CAA: Procedures and Criteria, Commonwealth Association of Architects, (approved by CAA Council, Beijing, China, June 1999, issued January 2000).

http://www.architectural-review.com/ar-awards/global-architecture-graduate-awards/enter-theglobal-architecture-graduate-awards-2013/8647111.article Retrieved on 20 Aug 2013.

${ }^{8}$ http://www.architectural-review.com/8650154.article /Retrieved on 20 Aug 2013.

9 http://www.architectural-review.com/8650352.article/Retrieved on 20 Aug 2013.

${ }^{10}$ http://www.portal.alexu.edu.eg/index.php/Retrieved on 20 Aug 2013.الصفحة الرسمية لجامعة الاسكندرية

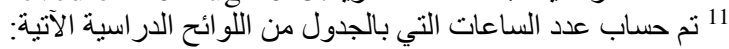

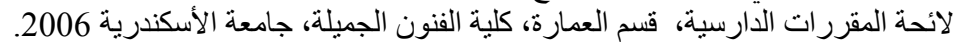

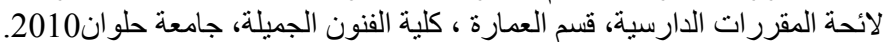

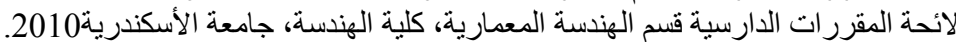

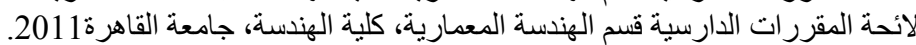
12 رصد ميداني من واقع العمل بالقسم.

13 Anne Beim: Tectonic Visions in Architecture, Copenhagen: Kunstakademiets Arkitektskoles Forlag, 2004, p12, 26, 35.

${ }^{14}$ Hilary Ballon: Louis Le Vau: Mazarin's Collège, Colbert's Revenge, 2001.

15 http://cu.edu.eg/ar/page.php?pg=contentFront/SubSectionData.php\&SubSectionId=30 الصفحة

Retrieved on 20 Aug 2013.الرسمية لجامعة القاهرة/2011/2

${ }^{16} \mathrm{http}: / /$ malgendy.wordpress.com/2011/03/17/ Retrieved on 20 Aug 2013.

17 http://www.ottowagner.com/home-en-us Retrieved on 20 Aug 2013.

18 http://www.bonah.org/news-extend-article-1356.html Retrieved on 20 Aug 2013.

19 http://www.asce.org/CEMagazine/Article.aspx?id=23622326068\#.UfLiVNJHKP4 Retrieved on 20 Aug 2013.

${ }^{20}$ http://www.designboom.com/architecture/frank-lloyd-wright-from-within-outward-exhibitionopens-at-the-guggenheim-nyc/ Retrieved on 20 Aug 2013.

${ }^{21}$ http://shredworld.wordpress.com/2010/10/18/louis-sullivan-in-iowa/Retrieved on 20 Aug 2013.

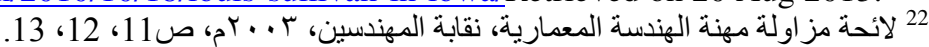
و ولاء يوسف: الاتجاهات الحديثة في التصميم المعماري، رسالة المئة دكتور اه، قسم العمارة كلية الفنون الجميلة، جامعة الاسكندرية.

Journal of Engineering Sciences, Assiut University, Faculty of Engineering, Vol. 41, No. 6, November, 2013,E-mail address: jes@aun.edu.eg 
${ }^{24}$ The British University in Egypt: Program Specification, Architectural Engineering,2009.

مصادر أخرى :

${ }^{25}$ The American University in Egypt: Program Specification, Architectural Engineering,2006.

26 لائحة المقررات الدارسية، مرحلة البكالوريوس كلية التخطيط العمر اني، جامعة القاهرة 2008.

\title{
STUDYING GRADUATION PROJECT, ARCHITECTURE DEPARTMENT, FINE ARTS FACULTY, ALEXANDRIA UNIVERSITY ACCORDING TO ACADEMIC CRITERIA, CURRICULUM, AND PRACTICING MARKET
}

\begin{abstract}
Developing Architectural Education is a top priority in Egyptian Public and Private Universities. As well; Architectural Department, Fine Arts Faculty fought several experiments to develop its regulations and curriculum to keep up with the International Architectural Education Standards. The study is concerning the most important course in the Department's scientific regulation; namely, Graduation Project, as an applied material, which evaluate the student's knowledge and background that is gained during Undergraduate Study. The Graduation Project curriculum was analyzed according to three factors as a criterion for course success; which are the educational standards, the teaching methodology, and architecture practicing market .Each factor was individually examined in parallel view. Studying the educational standards included Fine Arts Faculty and Architectural Department regulations, vision and goals, the standers of International Union of Architects, and the International Graduation Project Competitions regulations. Studying the teaching methodology included project's preparation, project's stages, and how did student address the system-wide to handle the course easily, that was through a questionnaire to discover how far the course achieves its objectives. Studying the relationship between Graduation Project and practicing market intended to show how far the course supported graduates' qualifications in different fields in architectural practicing market. The results of the analytical study for the mentioned three factors showed the course's strengths and weaknesses, which was the base for suggesting a proposal for developing the course's material that fits those factors as criteria. Finally, a number of conclusions and recommendation are derived.
\end{abstract}

Keywords: Architectural Graduation Project, Architectural Curriculum, Architectural Education, Architectural Practicing Market.

Journal of Engineering Sciences, Assiut University, Faculty of Engineering, Vol. 41, No. 6, November, 2013,E-mail address: jes@aun.edu.eg 